Orin

OAK RIDGE

NATIONAL

LABORATORY

MARTIN MARIETRA

\section{Electric-Utility DSM Programs: Terminology and Reporting Formats}

\author{
Eric Hirst \\ Carol Sabo
}


This report has been reproduced directly from the best available copy.

Available to DOE and DOE contractors from the Otfice of Scientific and Technical Information, P.O. Box 62, Oak Ridge, TN 37831; prices available from (615) 576-8401, FTS 626-8401.

Available to the public from the National Technical Information Service, U.S. Department of Commerce, 5285 Port Royal Rd., Springtield, VA 22161.

This report was prepared as an account of work sponsored by an agency of the United States Government. Neither the United States Government nor any agency thereof, nor any of their employees, makes any warranty, express or implied, or assumes any legal liability or responsibility for the accuracy, completeness, or usefulness of any information, apparatus, product, or process disclosed, or represents that its use would not infringe privately owned rights. Reference herein to any speriftc commercial product, process, or service by trade name, trademark, menufacturer, or otherwise, does not necesserity constitute or imply its endorsement, recommendation, or favoring by the United Staies Government or any afs zey thereof. The views and opinions of authors expressed herein do not necessarily state or reflect those of the United States Government or any agency thereof. 


\title{
ELECTRIC-UTILITY DSM PROGRAMS: TERMINOLOGY AND REPORTING FORMATS
}

\author{
ERIC HIRST AND CAROL SABO*
}

OCTOBER 1991

\author{
Sponsored by \\ Office of Conservation and Renewable Energy \\ U.S. Department of Energy \\ and \\ Customer Systems Division \\ Electric Power Research Institute
}

${ }^{*}$ Barakat \& Chamberlin, Inc., Washington, DC

OAK RIDGE NATIONAL LABORATORY

Oak Ridge, Tennessee 37831 managed by

MARTIN MARIETTA ENERGY SYSTEMS, INC.

under contract No. DE-AC05-84OR21400

for

U.S. DEPARTMENT OF ENERGY 


\section{TABLE OF CONTENTS}

page

PREFACE $\ldots \ldots \ldots \ldots \ldots \ldots \ldots \ldots \ldots \ldots \ldots \ldots \ldots \ldots \ldots \ldots \ldots$

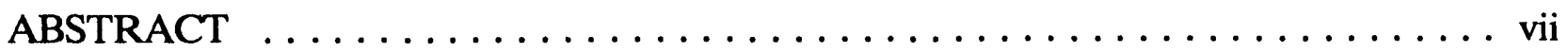

LIST OF ACRONYMS $\ldots \ldots \ldots \ldots \ldots \ldots \ldots \ldots \ldots \ldots \ldots \ldots \ldots \ldots \ldots \ldots$

1. INTRODUCTION $\ldots \ldots \ldots \ldots \ldots \ldots \ldots \ldots \ldots \ldots \ldots \ldots \ldots \ldots$

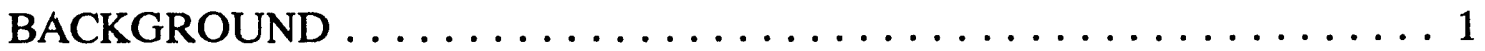

NEED FOR CONSISTENT DEFINITIONS $\ldots \ldots \ldots \ldots \ldots \ldots \ldots \ldots 3$

PURPOSE AND CONTENTS OF THIS HANDBOOK $\ldots \ldots \ldots \ldots \ldots 4$

USES FOR DSM-PROGRAM DATA $\ldots \ldots \ldots \ldots \ldots \ldots \ldots \ldots \ldots$

LEVEL OF DETAIL $\ldots \ldots \ldots \ldots \ldots \ldots \ldots \ldots \ldots \ldots \ldots$

2. TYPES OF UTILITY DSM PROGRAMS $\ldots \ldots \ldots \ldots \ldots \ldots \ldots \ldots$

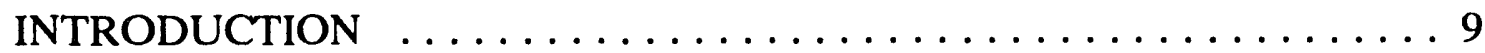

PROGRAM OBJECTIVES $\ldots \ldots \ldots \ldots \ldots \ldots \ldots \ldots \ldots \ldots$

CUSTOMER CLASS AND MARKET SEGMENTS $\ldots \ldots \ldots \ldots \ldots \ldots 10$

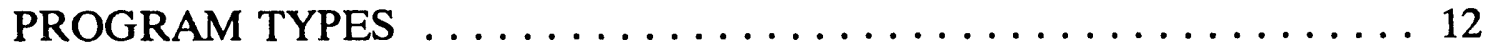

PROGRAM LIFE-CYCLE STAGE $\ldots \ldots \ldots \ldots \ldots \ldots \ldots \ldots \ldots \ldots$

3. PROGRAM PARTICIPATION $\ldots \ldots \ldots \ldots \ldots \ldots \ldots \ldots \ldots \ldots \ldots \ldots \ldots$

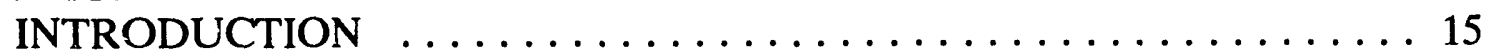

PARTICIPATING UNITS $\ldots \ldots \ldots \ldots \ldots \ldots \ldots \ldots \ldots \ldots \ldots \ldots \ldots$

MARKET DEFINITIONS $\ldots \ldots \ldots \ldots \ldots \ldots \ldots \ldots \ldots \ldots \ldots \ldots \ldots$

TYPES OF MARKETS $\ldots \ldots \ldots \ldots \ldots \ldots \ldots \ldots \ldots \ldots \ldots \ldots \ldots \ldots \ldots$

PARTICIPATION RATES $\ldots \ldots \ldots \ldots \ldots \ldots \ldots \ldots \ldots \ldots \ldots, 21$

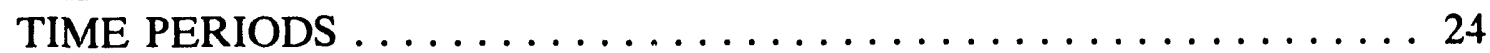

4. ENERGY AND LOAD EFFECTS $\ldots \ldots \ldots \ldots \ldots \ldots \ldots \ldots \ldots \ldots \ldots$

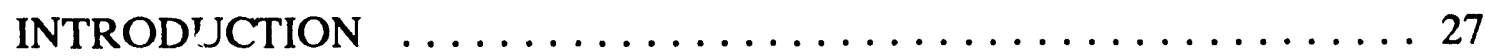

GROSS VERSUS NET EFFECTS $\ldots \ldots \ldots \ldots \ldots \ldots \ldots \ldots \ldots \ldots \ldots \ldots$

TEMPORAL DIMENSIONS OF EFFECTS $\ldots \ldots \ldots \ldots \ldots \ldots \ldots \ldots$

DATA AND ANALYSIS METHODS $\ldots \ldots \ldots \ldots \ldots \ldots \ldots \ldots \ldots, 34$

5. PROGRAM COSTS ............................... 39

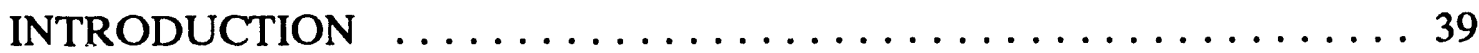

LEVEL OF DETAIL $\ldots \ldots \ldots \ldots \ldots \ldots \ldots \ldots \ldots \ldots \ldots \ldots$ 
ADMINISTRATIVE COSTS $\ldots \ldots \ldots \ldots \ldots \ldots \ldots \ldots \ldots \ldots$

MARKETING COSTS ...................... 44

MONITORING AND EVALUATION COSTS $\ldots \ldots \ldots \ldots \ldots \ldots \ldots 44$

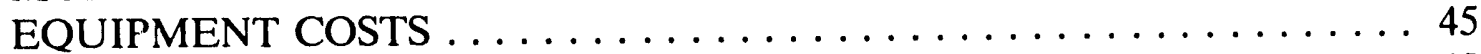

INCENTIVE COSTS ....................... 48

DEMAND-SIDE BIDDING PROGRAM COSTS $\ldots \ldots \ldots \ldots \ldots \ldots 50$

REGULATORY INCENTIVES $\ldots \ldots \ldots \ldots \ldots \ldots \ldots \ldots \ldots \ldots, 50$

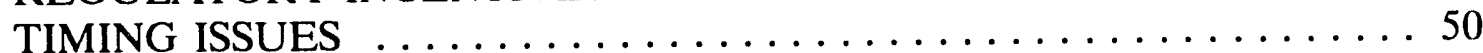

6. PUTTING THE DATA TO USE $\ldots \ldots \ldots \ldots \ldots \ldots \ldots \ldots \ldots \ldots$

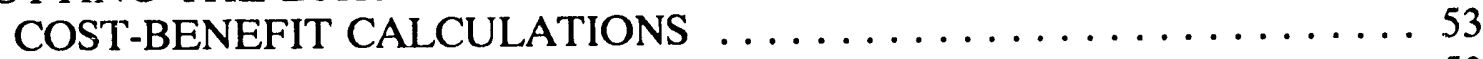

PROGRAM-PERFORMANCE INDICES $\ldots \ldots \ldots \ldots \ldots \ldots \ldots \ldots . \ldots \ldots$

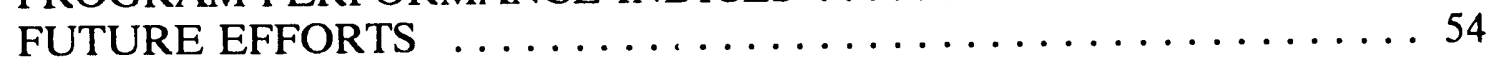

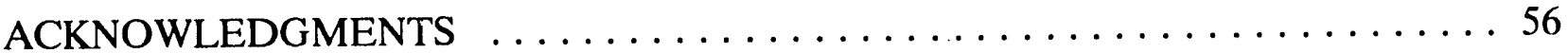

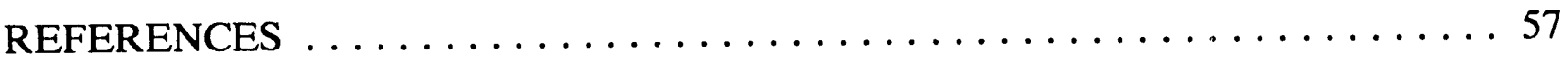

APPENDIX A: DSM-PROGRAM DATA REPORTING FORM $\ldots \ldots \ldots \ldots 63$

APPENDIX B: GLOSSARY OF KEY DSM-PROGRAM TERMS $\ldots \ldots \ldots \ldots 67$ 


\section{PREFACE}

We offer this report as a step on the path toward integrating demand-side management (DSM) into the business of providing consumers with low-cost electricity service. During the past decade, a growing number of electric utilities have begun to provide consumers with DSM services on a large scale. Across the nation, utility investments in energy efficiency increasingly are a key component of state plans to meet customer energyservice needs.

As utility DSM programs expand so does the work of describing them, comparing them, assessing their impacts, and evaluating their cost-effectiveness. While people in the DSM community talk to each other and learn from others' experiences, the language people use to describe, measure, and evaluate DSM programs often varies, and those variations often hinder our ability to communicate.

This report was prepared by people from the utility industry, utility regulators, and the U.S. Department of Energy who believe that DSM-program performance will be significantly improved by enhancing our ability to communicate with each other about DSM program plans, operations, and results.

This report is based on the work of several organizations that already have gone to great lengths to define terms and report results clearly. It builds upon these accomplishments and lays the ground work for significantly improving the way we report DSM information.

The next step will be the application of the recommended definitions and reporting format in this report to the day-to-day DSM program work now under way across the nation. This report is by no means the last word; on the contrary, by improving our ability to communicate, we hope to encourage more thought about DSM and ultimately to improve DSM performance.

Sam Swanson

Energy Conservation

Committee

National Association of

Regulatory Utility

Commissioners
Diane Pirkey

Office of Conservation and

Renewable Energy

U.S. Department of Energy
Philip Hanser

Customer Systems Division Electric Power Research Institute 


\section{ABSTRACT}

The number, scope, effects, and costs of electric-utility demand-side management programs are growing rapidly in the United States. Utilities, their regulators, and energy policy makers need reliable information on the costs of, participation in, and energy and load effects of these programs to make informed decisions. In particular, information is needed on the ability of these programs to cost-effectively provide energy and capacity resources that are alternatives to power plants.

This handbook addresses the need for additional and better information in two ways. First, it discusses the key concepts associated with DSM-program types, participation, energy and load effects, and costs. Second, the handbook offers definitions and a sample reporting form for utility DSM programs. The primary purpose in developing these definitions and this form is to encourage consistency in the collection and reporting of data on DSM programs. To ensure that the discussions, reporting formats, and definitions will be useful and used, development of this handbook was managed by a committee, with membership from electric utilities, state regulatory commissions, and the U.S. Department of Energy. Also, this data-collection form was pretested by seven people from six utilities, who completed the form for nine DSM programs. 


\section{LIST OF ACRONYMS}

BPA Bonneville Power Administration

DOE U.S. Department of Energy

DPS Department of Public Service

DPU Department of Public Utilities

DSM Demand-side management

EER Energy-efficiency ratio

EIA Energy Information Administration

HVAC Heating, ventilation, and air conditioning

NEPLAN New England Power Planning

NORDAX Northeast Region Demand-Side Management Data Exchange

PSC Public service commission

PUC Public utility commission

SIC Standard Industrial Classification 


\section{INTRODUCTION}

\section{BACKGROUND}

Throughout the United States, more electric utilities are running more and larger demand-side management (DSM) programs. For example, Fig. 1 shows that the New England Power Pool utilities plan to cut summer peak demand by $10 \%$ and annual electricity use by $5 \%$ by the year 2005 because of their DSM programs [New England Power Planning (NEPLAN) 1990a]. As shown in Table 1, some utilities plan even more aggressive DSM programs. An official from Pacific Gas \& Electric Company (Rueger 1991), the nation's largest utility, said:

In customer energy efficiency, PG\&E will spend close to $\$ 2$ billion over this decade. We intend to cut our energy growth by half and our peak demand by 75 percent $(2,500 \mathrm{MW})$ at an average cost of 3 to 4 cents per kilowatt-hour - less than half the levelized cost of building new fossil generation.

These programs are motivated by several factors. Perhaps the most important is the growing realization that DSM programs can provide large amounts of cost-effective energy and capacity resources that can reduce the need to build new power plants and transmission lines. In addition, DSM programs offer substantial environmental benefits over traditic nal utility supply resources. And public opinion strongly favors DSM programs over construction of power plants.

Because of these large potential benefits, public utility commissions (PUCs) in several states (especially California, Maine, Massachusetts, New Hampshire, New York, Rhode Island, and Washington) offer financial incentives to utilities that operate cost-effective DSM programs (Chamberlin and Hanser 1991). Typically, these incentives increase shareholder earnings on the basis of the net benefits provided to customers by these DSM programs. Net benefits are the difference between total benefits (based on improvements in efficiency of electricity use and reductions in peak demand) and program costs.

Finally, the 1990 amendments to the federal Clean Air Act provide 300,000 tons of sulfur-dioxide allowances to utilities that save electricity with their DSM programs or that produce electricity with renewable resources (U.S. Congress 1990).

This handbook offers definitions and sample reporting formats for utility DSM programs. Appendix A includes a sample form that utilities can use to report data on their DSM programs. Appendix B defines all the data elements on the sample form. And the following four chapters present the key issues and concepts associated with DSM program 


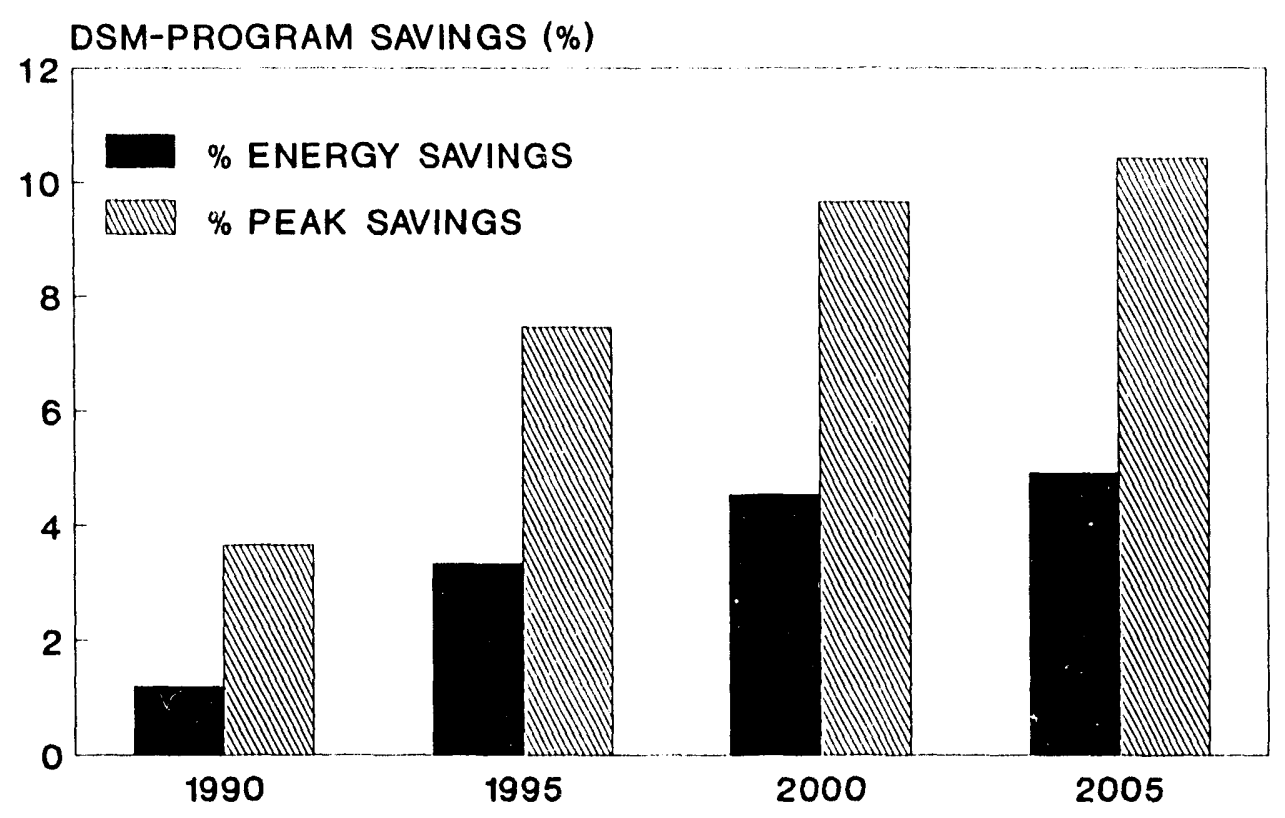

Fig. 1. Planned reductions in annual electricity use and summer peak demand caused by DSM programs run by the member utilities of the New England Power Pool.

Table 1. Sample of utilities with ambitious DSM programs

Utility (state)

Projected reductions in year-2000 electricity use and peak demand caused by utility DSM programs (\%) Energy savings

Peak reduction

Boston Edison (MA)

6.1

14.2

Central Hudson Gas \& Electric (NY)

3.9

7.6

Consolidated Edison (NY)

8.1

12.6

New England Electric System (NH, MA, RI)

6.6

13.7

Northeast Utilities (CT, MA)

7.0

9.3

Pacific Gas \& Electric (CA)

6.0

12.2

Puget Sound Power \& Light (WA)

6.8

Sacramento Municipal Utility District (CA)

13.5

Wisconsin Electric Power (WI)

Sources: Hirst (1991) and Nadel (1990b).

types, participation, eriergy and load effects, and costs. Our primary purpose in developing these definitions and formats is to encourage consistency in the collection and reporting of data on DSM programs. Although we urge utilities and PUCs to consider carefully the data 
elements and definitions presented here, we recognize that they are not intended to supplant existing data-collection systems. However, this report received extensive and detailed review from members of a Committee on DSM-Program Terminology (see the Acknowledgments). In addition, the Appendix A form was pretested with data on nine DSM programs from six utilities. We used results from this pretest to prepare the final version of this reporting forrn.

\section{NEED FOR CONSISTENT DEFINITIONS}

Whether DSM programs meet the ambitious goals discussed above depends strongly on the availability of data to document the performance of these programs. Unfortunately, the amount and quality of the data now available on DSM programs are far short of what utilities and regulatory commissions need (Berry 1989 and 1990; Hirst 1990; and Nadel 1990a). The current lack of explicit, widely used definitions of DSM-program terms is a key deficiency that makes it difficult to assess the contributions that such programs could make to meeting future energy-service needs. In essence, we now discuss DSM programs in a "tower of babel," leading to disparate estimates of DSM potential and performance.

A hynothetical example will illustrate the problems caused by different and unstated definitions. Consider two utility programs that encourage the installation of low-flow showerheads (Table 2). The two utilities show very different estimates of program costs, participation rates, energy savings, and cost effectiveness. Casual Power \& Light computed electricity savings on the basis of engineering calculations that relied on narrow assumptions about customer usage and acceptance of the new showerheads. On the other hand, Rigorous Power measured flow rates with the original showerheads and the low-flow showerheads (3.2 vs 1.6 gallons/minute), collected data on the time spent taking showers with both types of showerheads ( $5 \mathrm{vs} 6$ minutes/shower), and estimated the fractions of customers that would have installed the low-flow showerhead without the utility program (10\%) and that would remove the new showerheads soon after installation (20\%). These differences lead to the much lower, but more realistic, estimate from Rigorous Power of the electricity savings per participant.

Similar differences occur for the estimates of costs, participation rates, and cost effectiveness. Casual Power \& Light considered only the cost of the showerhead, while Rigorous Power included also the cost of utility administration and marketing. Casual Power \& Light based its participation estimates on its total residential class, while Rigorous Power based participation rates on the number of residential customers with electric water heaters.

This example shows the variation in reported results that can occur with different definitions. The problem is not only with the use of different definitions but also with the explicitness of these definitions. Thus, the user of such data does not know whether or how data can be compared across programs. (In this example, Casual Power \& Light reported its estimate of gross electricity savings based on assumptions, and Rigorous Power reported its estimate of net electricity savings based on field data. 
Table 2. Hypothetical situation showing different estimates of the costs, participation, and electricity savings from DSM programs

Casual Power and Light

Savings $=450 \mathrm{kWh} /$ year per participant

Participation $=1 \%$ of residential customers per year

Cost of conserved energy $=0.5$ cents $/ \mathrm{kWh}$

Annual savings $=2.7 \mathrm{GWh}$

Rigorous Power

Savings $=270 \mathrm{kWh} / \mathrm{year}$ per participant

Participation $=3 \%$ of electric water heater customers per year

Cost of conserved energy $=1.2$ cents $/ \mathrm{kWh}$

Annual savings $=1.9 \mathrm{GWh}$

In essence, we need to develop definitions for DSM programs just as we have for power plants. The terms availability factor, capacity factor, heat rate, and variable operations and mainterance costs are well defined and widely used by electric utilities throughout the country. Similarly, utilities and PUCs need clear, consistent, and widely used definitions for program participation, energy and demand savings, and program costs. The California PUC (1991) noted that:

Consistent treatment of [utility DSM programs] is particularly important for determining program cost-effectiveness and funding levels, for measurement and evaluation activities, and in the treatment of shareholder incentives. Establishing consistent treatment requires a common terminology. ... As a first step, we propose to adopt definitions for utility DSM programs.

\section{PURPOSE AND CONTENTS OF THIS HANDBOOK}

This handbook is aimed primarily at utility, PUC, and government agency staff who plan and manage DSM programs, do utility-resource planning, and analyze energy-policy alternatives. The primary purpose of this volume is to present commonly used definitions for the key terms that characterize DSM programs (Appendix B) and to suggest a simple format (Appendix A) that utilities can use in collecting and reporting such data to their own management, to PUCs, and to the federal government. We discuss a variety of issues related to the documentation of DSM-program performance, but only the most important terms are included in the suggested reporting format. The following four chapters deal, respectively, with program types, program participation, program energy and load impacts, and program costs. 
Clearly, this volume is not the first attempt to define DSM program $t$.rms. Earlier efforts, on which this handbook rests, include those from the Maine PUC (Bergeron and Parker 1989), the California PUC (1990), the Energy Information Administration (EIA 1991), the Massachusetts Department of Public Utilities (DPU) (1989), New England Power Planning (1990b), the New York Department of Public Service (DPS) (1990a), NORDAX (1989a and 1989b), and the Wisconsin Public Service Commission (PSC) (1990). The Edison Electric Institute (1991) just updated its Glossary of Electric Utility Terms; the 1991 version includes many more DSM terms than did the 1984 edition.

Just as clearly, this volume is not the final word on DSM-program definitions. Surely, these definitions will evolve over time as they are used and as DSM programs grow in importance and scope. In tuis early effort, we strive for simplicity. Rather than develop a data collection and reporting system that is very detailed (and therefore complicated), we chose to develop a system that is more aggregate, easier to use, and therefore more likely to be usable and useful. We focused on the minimum data needed to characterize DSM programs. Later efforts may expand the scope and detail of this project.

\section{USES FOR DSM-PROGRAM DATA}

Data on DSM programs are useful within the utility (Fig. 2), for other utilities planning similar programs, for regional power pools, for state regulatory commissions, for state and federal energy planners, and for other groups interested in energy issues.

Utilities produce these data to document the costs and performance of their programs; that is, for program evaluation. This information is used to make decisions concerning program modification, expansion, or cancellation. Such data are also useful within the utility for load forecasting, market research, load research, rate design, and integrated resource planning. Where these issues are handled by cifferent departments, clear agreement on definitions is essential to a utility's internal communication.

For utilities just beginning to plan their DSM programs, information on existing programs at other utilities is often the only source of estimates on program costs, participation rates, energy and demand reductions, and cost effectiveness. Such "borrowed" data are useful only if the definitions that underlie these data are clear and consistent from utility to utility.

Utilities and PUCs also use data from different utilities to compare results for similar programs across utilities and to determine the amount of incentives paid to utility shareholders for their DSM programs. Such "yardstick" comparisons allow utilities and PUCs to assess their performance (Nadel 1991). Exhibit 1 illustrates the problems that Ontario Hydro had in making sense of data from various utilities in North America. Statistical analysis of program data (e.g., to analyze program cost effectiveness as a function of utility financial incentive, utility marketing budget, length of time program has been in existence, program type, electricity prices, and so on) requires data for similar programs 
from many utilities. Such analyses cannot be conducted unless the definitions used to characterize these programs are consistent.

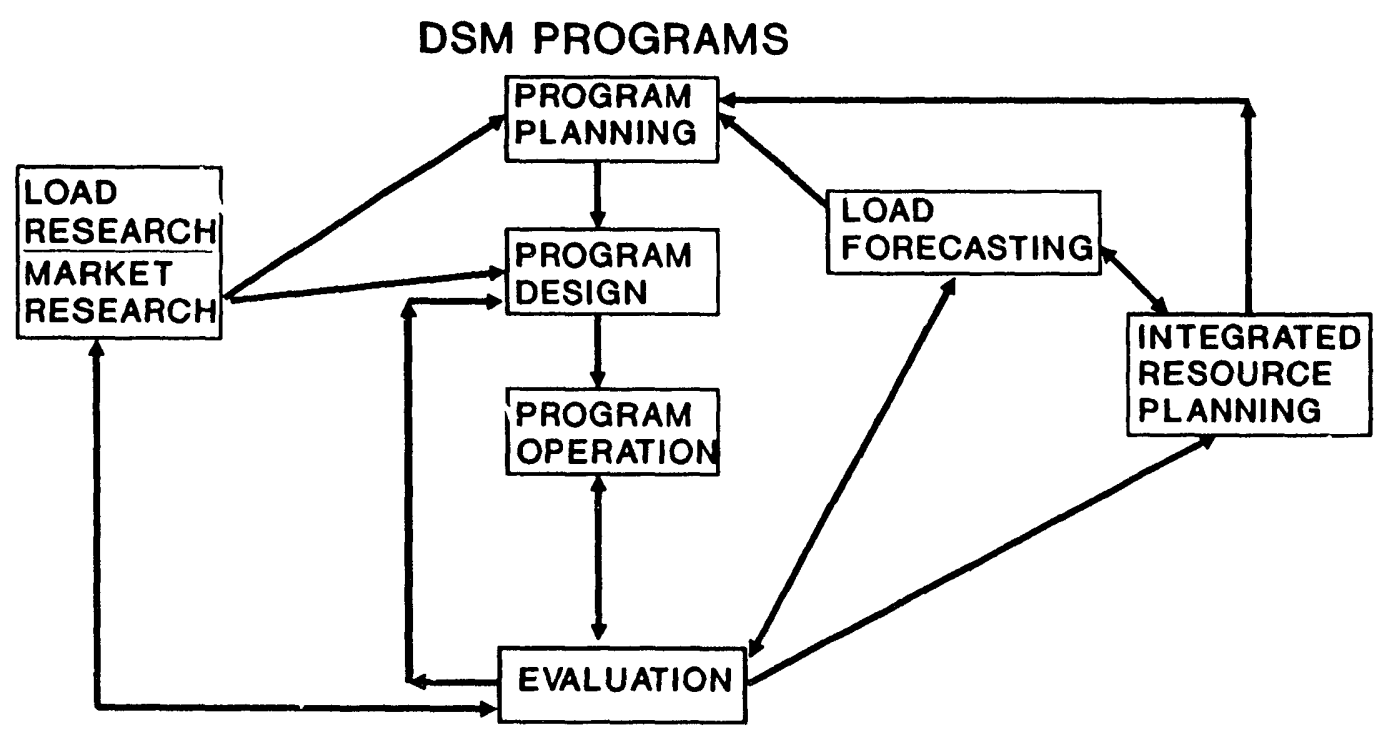

Fig. 2. Data on DSM programs are useful for several activities within utilities, including DSM-program planning and design, market research, load research, load forecasting, evaluation, and integrated resource planning. Such data are also used to report results to regulatory commissions.

\section{LEVEL OF DETAIL}

Data on DSM programs are needed at different levels of detail. Utility staff responsible for day-to-day operation of individual DSM programs will want very detailed information on the individual technologies being promoted and on the marketing methods being used. The structure developed by the Northeast Region Demand-Side Management Data Exchange (NORDAX 1989a and 1989b), which includes information on individual DSM end-use technologies, is suitable for such people.

However, if the data-collection system calls for too much detail, program staff will not be able to complete the data-collection forms. These problems will occur because staff have insufficient time and because some data do not exist (i.e., were not collected). The resultant data base will then have missing data elements for some programs. To illustrate, the 1991 NORDAX data base included data on 46 full-scale programs that had been in operation for more than one year (of about 150 programs in the data base). However, complete information on participation rates, program costs, and energy or load reductions was available for only 18 of these programs. Also, utilities frequently bundle various technologies into one program, making it difficult to use the technology as the unit of observation when discussing DSM programs. 


\section{Exhibit 1. Problems in comparing data across utilities.}

Ontario Hydro, as part of its planning for new and expanded DSM programs, studied programs run by electric utilities throughout North America. The study on residential programs covered 10 utilities and 24 programs (Schick et al. 1990 and Ontario Hydro 1991). This effort focused on program participation rates and the factors that affect these rates.

Unfortunately, analysis of these data failed to yield meaningful relationships. Figure 3 shows the relationship between annual participation rate and the utility's financial incentive to participants for these 24 programs. The correlation between these two factors $\left(R^{2}\right)$ is essentially zero. In other words, these data show no relationship between the frac::on of DSM-investment cost $p: d$ by the utility and participation in that program. A broader analysis examined the influence on program participation of the time the program had been in existence, residential electricity price, and the ratio of incentive costs to total program costs. A regression model with these three factors as independent variables explained only $8 \%$ of the variation in participation rates across these programs. Also, none of the coefficients was statistically significant at the $10 \%$ level.

What accounts for this inability to explain statistically the interprogram variation in participation rates? Surely, inconsistency in definitions across programs and utilities helps to explain these poor results. Differences in marketing approaches, consumer discount rates for purchase of different types of appliances, and other factors also account for the poor explanatory power of this model. Utilities define participation rates, financial-incentive fractions, and program lifetimes in various ways. For example, participation rates can be expressed on a cumulative or annual basis. And both the numerator and denominator of a participation rate can be defined in different ways.

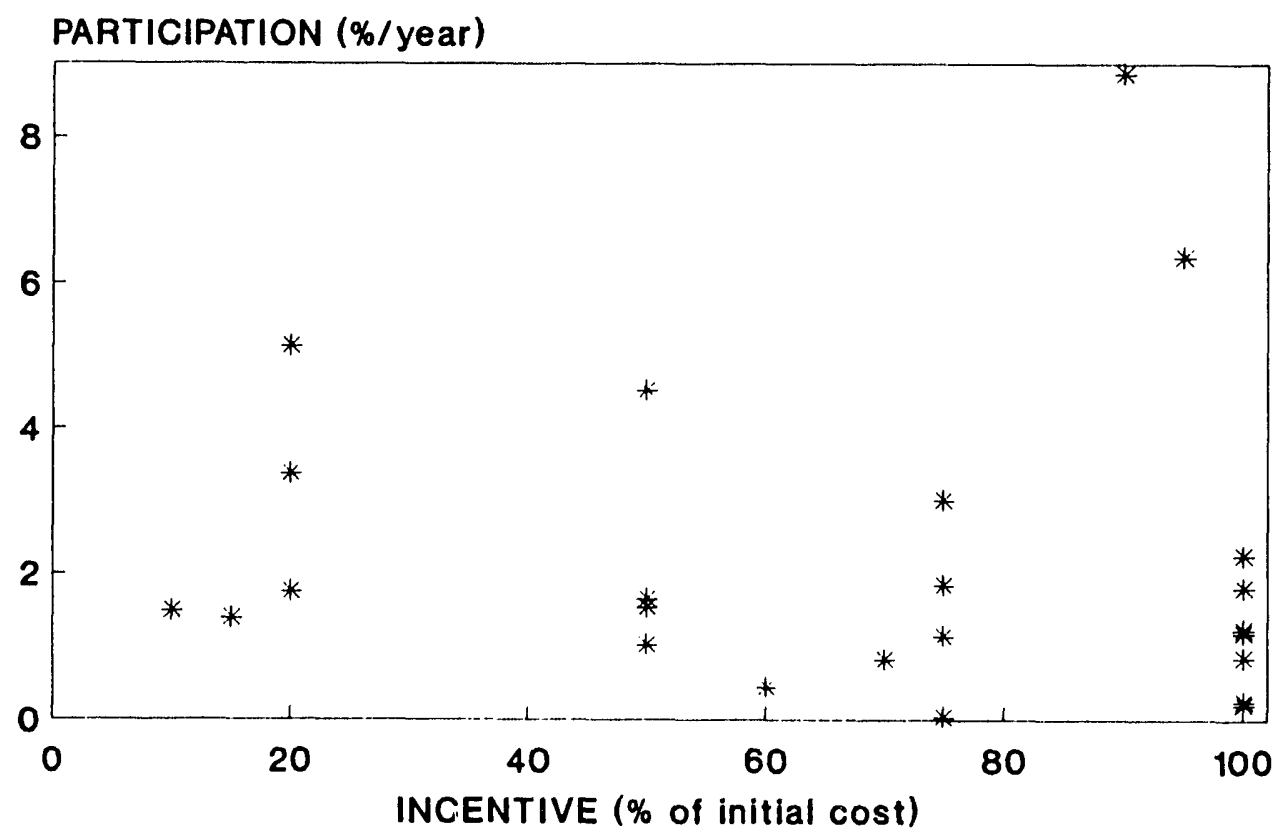

Fig. 3. Annual participation rates and incentives for residential energy-efficiency programs. These programs include new-home construction, energy audits, efficient appliances, water heating, heat pumps, air conditioning, and lighting. 
At the other end of the spectrum, policy analysts at the U.S. Department of Energy (DOE) and other national organizations want data aggregated to the utility level. EIA (1991) developed Schedule 5 of EIA-861, a form that collects data on the utility's overall DSM accomplishments, plans, and costs on an annual basis. 'This type of aggregate data is suitable at the state, regional, and national levels to assess overall progress and to compare performance across utilities.

In betweer, resource planners and managers at utilities and staff at regulatory commissions will want intermediate levels of disaggregation.

Possible levels of disaggregation include technology, end use, customer, program, customer class, or utility. This handbook treats the program as the unit of observation." DSM programs $^{\#}$ are organized utility activities that affect the amount and timing of customer electricity use. Unlike NORDAX, the definitions developed here do not deal with the individual technologies offered by a program or those the program aims to replace. A recent survey of NORDAX members showed a strong preference for a simpler system because the current "data base is complicated to use and requires significant training" (Ciliano and Hinkle 1991). On the other hand, our approach is more detailed than the EIA form, which treats the utility as the unit of observation.

Comprehensiveness of program reporting is another issue related to level of detail. We recommend that utilities report data on only their major DSM programs. Small programs that are inexpensive and have only minor energy and capacity effects (e.g., general information programs) could be aggregated and reported in an "other" category. This additional category is needed to ensure that the sums of energy and load effects and program costs across individual programs add up to the correct utility totals. For example, almost half of the 379 programs in the NEPLAN (1990a) 1990 DSM-program data base together accounted for less than $2 \%$ of the estimated energy savings and peak-demand reductions. On the other hand, 35 programs (less than $10 \%$ of the total number) accounted for almost $75 \%$ of the total savings.

Because data on DSM programs can treat different levels of disaggregation, it is essential that the terms used to define a particular program be internally consistent. For example, the time periods (e.g., calendar year 1990) used to describe program costs, participation, and energy effects must all be the same. And the method of defining participation must be consistently applied because estimates of program cost and energy impacts are often expressed on a per-participant basis.

*For a variety of reasons related to program design, operation, and regulatory review, utilities may still need to collect data on individual participants and the DSM technologies and operating practices they adopt.

*Terms that are shown in bold are included in the Appendix B glossary. 


\section{TYPES OF UTILITY DSM PROGRAMS}

\section{INTRODUCTION}

This chapter discusses several characteristics of DSM programs that affect the definitions of participation, energy and load impacts, and costs. These characteristics include: objective(s), customer class or market segment at which the program is aimed, program type, and program lifecycle stage. Differences among program types affect the kinds of data that can be collected and the definitions of program terms. For example, participation rates are defined differently for programs aimed at new construction than for retrofit programs. Participation in new-construction programs is limited to buildings constructed while the program is in effect. However, all the utility's customers may be eligible for a retrofit program. (Although this handbook often refers to energy savings and load reductions, note that certain DSM programs can lead to increases in energy use.)

\section{PROGRAM OBJECTIVES}

The primary purpose of most utility DSM programs is to affect the level and timing of electricity use. Typical objectives include energy efficiency, peak clipping, load shifting, valley filling, and load building. These objectives differ in their effects on electricity use $(\mathrm{kWh})$ and instantaneous demand $(\mathrm{kW})$. Programs often have more than one objective. For example, thermal-storage programs reduce peak demands, increase off-peak consumption, and shift loads from on-peak to off-peak periods. Load shape refers to the temporal pattern of customer electricity use, typically over a 24 -hour day or a full 8760 -hour year.

Energy-efficiency programs (sometimes called energy-conservation programs) are aimed at improving the energy efficiency of specific end-use devices and systems. Such programs usually reduce overall electricity consumption $(\mathrm{kWh})$, often without regard for the timing of program-induced savings. Generally, energy savings are achieved through the substitution of tech inically more efficient DSM measures (i.e., equipment, systems, and/or operating procedures) to produce the same level of end-use service (e.g., lighting or warmth) with less electricity.

Peak-clipping programs aim to reduce electricity demand (kW) at certain critical times, typically when the utility experiences system peaks. These programs generally have only small effects on overall electricity use, but focus sharply on changes in the timing of electricity use. Some peak-clipping programs are dispatchable, which means that the utility can directly control their effects. For example, cycling residential air-conditioners is 
considered a dispatchable program because the utility can decide whether and when to deploy this option.

Load-shifting programs aim to move electricity consumption from one time to another (usually during a single day). For example, water-heater timers typically turn off the units during the daytime (when the utility experiences peak deniands) and allow the units to operate at night (during the utility's off-peak period). Time-of-use rates encourage load shifting because they increase electricity prices during peak periods and reduce prices during off-peak periods. Load-shifting and peak-clipping differ because the former shifts much of the electricity use from one time to another, while the latter eliminates a load without shifting it to another time period.

Valley-filling programs typically seek to increase off-peak electricity consumption (without necessarily reducing on-peak demands). Replacement of a natural-gas-fired furnace with an electric heat pump (with backup heat provided by natural gas) is an example of valley filling. Such programs can aim to fill daily or seasonal valleys.

Load-building programs aim to increase electricity consumption, generally without regard to the timing of this increase. Promotion of residential electric space heating systems and promotion of new industrial electrotechnologies are examples of load-building programs.

\section{CUSTOMER CLASS AND MARKET SEGMENTS}

Most programs are aimed at specific subsets of the utility's total population of customers. Some programs address a particular customer class, a group of customers with similar characteristics, such as economic activity or level of electricity use. Typical customer classes include residential, commercial, industrial, and several smaller classes (e.g., agricultural, street and highway lighting, other public authorities, and railroads).

Each class can be further subdivided. The residential sector is often subdivided by housing type: single-family, multifamily, and mobile home. Sometimes, the residential sector is split according to the use of electricity for space heating, water heating, or both. This type of split may occur when the utility offers different rate structures for households with different types of electricity-using equipment. Programs are sometimes marketed to different groups of residential customers based on such characteristics as home ownership, age of household head, or income. Many utilities, for example, operate special programs aimed at low-income households.

The commercial sector, broadly defined as businesses that provide services, is often defined by building type, activity type, or Standard Industrial Classification (SIC) code. The activities used by EIA (1989) in its Commercial Buildings Energy Consumption Survey are shown in Table 3 along with the seven building types used in EIA's commercial building energy forecasting model (EIA 1990). The Commercial End-Use Planning Model, developed for the Electric Power Research Institute, has 11 building types: small office, 
large office, restaurant, retail, grocery, warehouse, school, college, health, lndging, and miscellaneous. The SIC codes 40 through 99 are usually considered commercial (Table 4). The SIC system defines industries at the two-, three-, and four-digit levels. Health Services (80) includes Hospitals (806), which includes Psychiatric Hospitals (8063).

The industrial sector, broadly defined as businesses that provide protucts, is often defined by SIC code along the lines shown in Table 4. The SIC categories from 1 through 39 are generally considered industrial (agriculture, mining, construction, and manufacturing). The same disaggregation from two- to four-digit groups mentioned above exists for the industrial sector; to illustrate, Primary Metals (33) includes Iron and Steel Foundries (332), which, in turn, includes Steel Investment Foundries (3324). Some utilities (e.g., those that serve rural areas) split the agricultural sector from the rest of the industrial sector. Agriculture includes production of crops and livestock; forestry; and fishing, hunting, and trapping.

The commercial and industrial sectors are often classified by rate class. Each rate class is defined on the basis of voltage level of service, amount of electricity consumed per billing period, and peak demand. Substantial overlap often occurs between customer classes and rate classes.

Table 3. Classification system useci by the Energy Information Administration for commercial buildings

Commercial buildings survey

Office or professional

Retail/wholesale sales and services (except food)

Public assembly

Food sales

Public order and safety

Outpatient health services

Industrial Processing or inanufacturing

Agricultural purposes

Laboratory

Refrigerated warehouse or storage

Nonrefrigerated warehouse or storage

Education

Food services

Hospital/inpatient health service
Skilled nursing or other residential care facility

Hotel, motel, or other short- or long-term accommodations

Residential

Indoor enclosed parking garage

Commercial forecasting model

Warehouse

Retail/wholesale

Food sales/service

Office

Education

Continuous use

Miscellaneous

Sources: EIA (1989 and 1990). 
Table 4. Industries in the standard industrial classification system

Agriculture, forestry, and fishing (SIC codes 1-9)

Mining (10-14)

Construction (15-17)

Manufacturing (20-39)

Transportation, communications, electric, gas, and sanitary services (40-49)

Wholesale trade $(50-51)$

Retail trade (52-59)

Finance, insurance, and real estate (60-67)

Services (70-89)

Public administration (91-97)

Nonclassifiable establishments (99)

Source: Executive Office of the President (1987).

Programs are often aimed at narrower market segments than a customer class or rate class. As illustrations, programs may be targeted to low-income households iri multifamily units, to small- and medium-size office buildings, or to farmers with electric irrigation pumps.

\section{PROGRAM TYPES}

DSM programs differ in the types of services offered to customers. Programs can provide general information, site-specific information, direct installation, financial incentives, alternative rates, or a combination of these services.

General information programs refer to utility efforts to inform customers about DSM options through such mechanisms as brochures, bill stuffers, and workshops. Site-specific information programs often involve an onsite inspection of the customer facility to identify cost-effective DSM actions that could be taken. For new construction programs, such targeted information can take the form of technical assistance to architects and engineers who design new facilities.

Direct-installation programs involve utility installation of DSM measures; such programs generally cover low-cost measures, such as water-heater wraps and compact fluorescent lamps. In many cases, the measures are installed at no cost to participants.

Incentive programs provide cash or noncash awards to customers or trade allies to encourage the purchase or sale of program-sponsored DSM measures. Appliance rebate programs are the most common example of incentive programs. Incentives can also include zero- or low-interest loans. 
Alternative-rate programs offer special rate structures or discounts on the customer's monthly electric bill, generally in return for participation in programs aimed at cutting peak demands. For example, utilities often pay customers several dollars a month (refunded on their monthly electric bill) for participation in a load control program. Large commercial and industrial customers sometimes obtain interruptible rates, which provide a discount in return for the customer's agreement to cut electrical loads upon request from the utility (usually during critical periods, such as summer afternoons when the system demand approaches the utility's generating capability). Time-of-use rates are another form of alternative rates that encourage customers to shift electricity use from on-peak to off-peak times.

Fuel-switching programs encourage customers to change from one fuel to another for a particular end-use service. As examples, utilities might encourage customers to replace electric water heaters with gas units or encourage industrial customers to use electric microwave heaters instead of natural-gas heaters.

Programs also differ in their delivery mechanism. Programs are delivered by utility staff, by contractors hired by the utility to accomplish certain tasks (e.g., wrap residential water heaters or conduct energy audits of commercial buildings), by energy service companies that contract with utilities to deliver energy and load reductions in certain market segments, or by government agencies.

\section{PROGRAM LIFE-CYCLE STAGE}

Programs also differ in scope. At one end of the spectrum are small-scale experiments intended to test various concepts associated with a DSM program. These concepts might include alternative marketing approaches, various types and levels of financial incentives, or different technologies aimed at improving efficiency of a particular end use. Such efforts are really not programs because they are intended primarily to collect information rather than to acquire energy and capacity resources.

At the other end of the spectrum are full-scale programs (mature, systemwide programs) that are available to all of the eligible customers in the utility's service area. In between are pilot programs, which usually represent the initial phases of a full-scale program. During the pilot phase, a program may be cffered to customers in only one of the utility's divisions. This phase is used to iron out the bugs associated with implementing a new program and to allow time to hire staff, develop accounting systems, secure supplies, and so on to conduct a full-scale program. 


\section{PROGRAM PARTICIPATION}

\section{INTRODUCTION}

Program participation is a major factor in the success of a DSM program. A program's energy and load effects are directly related to the number of customers and/or trade allies (businesses that sell or inilience choices of energy-using equipment, including appliance dealers, architects, and builders) participating in the program. When predicting participation rates for new programs, utilities often rely on other utilities' experience. Such data are often difficult to interpret because of differences in the ways utilities calculate and report program market and participation data.

A program participation rate is the ratio of the number of participants to the number of customers eligible for the program. These rates are calculated as a percentage of a base market (the largest market against which participation is measured), usually the eligible market. Eligible market is defined by the eligibility criteria for the program (e.g. all residential customers with electric water heaters). Utilities use different terms to describe the market for a particular program, including total market, eligible market, target market, and potential market. The potential market can be further defined based on estimates of technical, economic, and market potentials.

All programs fit into one or both of two categories: (1) programs that affect the way energy-using equipment is operated and (2) programs that focus on the installation of improved technologies (i.e., building shell, appliances, equipment, and industrial processes). In the second type of program, utilities use various terms to describe the market, including new, retrofit, early replacement, normal replacement, and early retirement.

The definition of participating units, the number of years the program has operated, the identification of the market type, and the estimation of market size affect the calculation of participation rates. The units used to describe the participants and the market can be number of customers, number of buildings, floor space, $\mathrm{kW}$ of end-use load, or units of equipment (e.g., number of water heaters). The appropriate unit will vary by customer class and type of DSM equipment or program.

\section{PARTICIPATING UNITS}

Defining the number of participants and the number of eligible customers for a program can be complicated. Results differ depending on whether account numbers, meters, customers, or buildings are used. For example, several customers could reside in the same 
multipurpose commercial building, including a restaurant, a bank, and several firms occupying office space. A large industrial firm might have several meters at a single plant site.

Customers or households are often used as the participating unit for residential programs. Customers are those households that directly pay their electricity bills. A household is a person or group of people who share a dwelling unit. Some households consume electricity but do not directly pay the bill. For commercial and industrial customers, utilities frequently use other units, such as connected load in $\mathrm{kW}$, number of buildings, square feet of floor space, units of equipment and appliances, horsepower of motors, and tons of air conditioning (Table 5).

Table 5. Examples of participating units for various types of programs

\begin{tabular}{lll}
\hline Customer segment & Type of program & Participating unit \\
\hline Residential & $\begin{array}{l}\text { High-efficiency } \\
\text { refrigerator }\end{array}$ & $\begin{array}{l}\text { Customers, households, or refrigerators } \\
\text { installed }\end{array}$ \\
Residential & $\begin{array}{l}\text { Water-heater } \\
\text { conservation }\end{array}$ & $\begin{array}{l}\text { Customers, households, number of water } \\
\text { neaters retrofit, or number of measures } \\
\text { installed }\end{array}$ \\
Commercial & Cool-storage systems & $\begin{array}{l}\text { Customers, buildings, or tons of air } \\
\text { conditioning installed }\end{array}$ \\
Commercial & High-efficiency lighting & $\begin{array}{l}\text { Customers, buildings, lamps, fixtures, or } \\
\text { floor area }\end{array}$ \\
Industrial & Interruptible rate & Customers or $\mathrm{kW}$ demand \\
\hline
\end{tabular}

More than one participating unit can be identified for a program. For example, NORDAX (1990) reports both a customer unit and a technology unit. The customer unit relates to customers, households, or buildings, while the technology unit is based on the enduse technology, which is the device that consumes electricity or affects the way electricity is consumed. Square footage of floor area for lighting and $\mathrm{kW}$ installed for electric thermal storage heating are examples of technology units. In contrast, the Massachusetts DPU (1989) requires the utilities to report program participation based strictly on customers. Others, such as the Wisconsin PSC (1990), report participation based on a program unit that may include either customer units or technology units. In some cases, program participarits are not even reported. Both EIA (1990) and NEPLAN (1990b) require only peak load and energy savings and program cost data. 
The definitions of participating units and the eligible market (for calculation of the participation rate) should be identical. In the case of an apartment-building audit program, the participating unit could be a household, dwelling unit, apartment building, meter, or the entire apartment complex, depending on the specification of the eligible market. But the definition should be the same for both participants and the eligit'e market.

The participating unit can even be a customer who is unaware of the program. For example, Consolidated Edison offers gif's to appliance dealers for promoting efficient refrigerators and air conditioners. The appliance purchaser does not know that he or she is participating in a program. Information on the number of participating dealers is important in reviewing the performance of this program. For calculating load impacts and participation rates based on eligible units, however, the participating unit should be defined as the qualifying air conditioner sold or the customer making the purchase.

Participating units include all customers who can be identified as participating in the program, including free riders, customers who would have adopted program-recommended measures even without the program, but who participate in the program. For example, Long Island Lighting Company conducted a voluntary time-of-use rate program for residential customers in 1989 (Sabo, McRae and Donner 1990). The program's evaluation showed that many customers were already using appliances during off-peak hours before volunteering to participate in the time-of-use rate program (i.e., they were free riders).

Free drivers are customers who adopt measures as a result of the program's infiuence, but who do not directly participate (e.g., they do not apply for rebates even though tie appliance they purchased qualifies for the utility rebate). They are not normally identified at the time of purchase and are not treated as participants. Free riders and free drivers are discussed further in Chapter 4.

It is easier to track the number of participating units in programs that require the installation of equipment or devices. It is more difficult to measure participation in programs that promote voluntary changes in operations (e.g., changes in thermostat settings) or that provide general information.

Timing is an important factor in calculations of participation for certain types of DSM programs. A water-heater blanket may be installed for a residential program soon after the customer agrees to participate in the program. For certain types of commercial and industrial programs, however, months and even years may elapse between application to participate and installation of all equipment. A customer could elect to participate in a newconstruction program promoting efficient heating, ventilation, and air conditioning (HVAC) systems during the design phase of the customer's building, while equipment installations would not be completed until a year or more later.

The Massachusetts DPU (1989) specifies that "program participation should be based on installed savings, as opposed to contracted savings," but different utilities define program participation differently. Participation is more difficult to define for some programs than 
others. For example, Table 6 identifies the major steps in a residential retrofit program, each of which could be used to define program participation.

Table 6. Major steps in a residential retrofit program that can be used to define participation

1. Customer accepts utility offer of free audit

2. Utility conducts audit

3. Customer requests preapproval of rebate for recommended measures

4. Contractor installs measures

5. Utility inspects installed measures

6. Utility processes rebate check

Question: When does the customer become a participant?

In this example, double-counting impacts is a definite risk. The energy and demand impacts caused by the energy audit should be kept separate from the savings caused by the retrofit measures if they are installed under a separate rebate program. Tracking participation in programs where the same customer can participate more than once may also be difficult. The calculation of participation rate may be less meaningful if the same customer is counted several times as a participant.

In many cases, timing is not specifically addressed in DSM-program-reporting requirements. The utility can incur significant expenses for a potential participant before equipment or measures are installed. For those types of programs, a separate category of committed-but-not-yet-installed participants could be included.

\section{MARKET DEFINITIONS}

A number of terms, based on various market definitions, refer to the potential number of participating units. They include total market, potential market, eligible market, and target market.

The potential market can be identified in three ways: technical potential, economic potential, and market potential (Fig. 4). Technical potential is the amount of savings possible if all existing electricity-using equipment, buildings, and industrial processes are replaced with the most efficient commercially available systems regardless of cost. The Massachusetts DPU (1989) defines the most efficient technologies as "state-of-the-art commercially available", while the Wisconsin PSC (1990) regulations describe them as equipment that "has been developed and tested and is available in the current marketplace or will be in the near future." Two types of technical potential exist: instantaneous and 
phased-in. Instantaneous technical potential assumes that all existing devices are instantly replaced with the most efficient devices. Phased-in technical potential assumes that only new equipment needs (including normal additions and normal replacements) will be replaced with the most efficient available on the market. Stock turnover involves replacement of existing equipment, while add-ons are additions to existing stock.

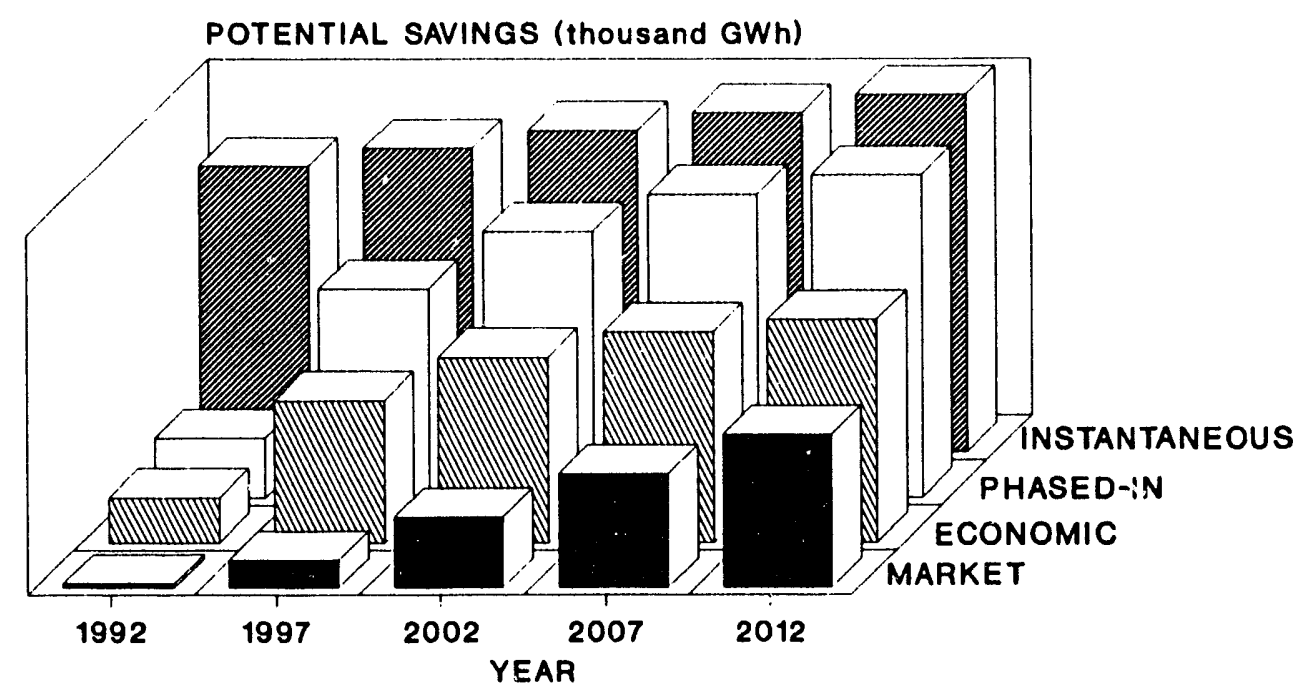

Fig. 4. Schematic showing the differences among technical, economic, and market potentials for a utility DSM program.

Economic potential represents the portion of technical potential that is cost-effective. Cost-effectiveness can be based on the perspectives of the participant, the utility, all ratepayers, or society as a whole; see Chapter 6. Market potential represents the portion of economic potential that a particular program is expected to achieve, considering that customers do not always make decisions based strictly on economics.

The New York DPS (1990c) required the New York utilities to assess the "economic and achievable DSM potential" in their respective service areas. Economic potential was defined as "economic from a total-resource perspective" while achievable potential was defined as the portion of that economic potential "that may be achievable through utility DSM programs."

The total market for a particular program is often defined as the total customer base for that class of customer (e.g., all commercial customers). The program's eligibility criteria are used to establish the eligible market, the subset of the total market that is eligible to participate in the program (e.g., all residential customers with electric space heating or all 
commercial buildings with more than 100,000 square feet in floor area). The target market is the subset of the eligible market that serves as a focus for utility marketing efforts (e.g., has the greatest potential for load reductions).

The eligible market must also reflect saturation of the DSM technologies or measures promoted by the program. Saturation refers to the number of a specific type of equipment in place as a fraction of the total stock of equipment or buildings (e.g., the fraction of residential refrigerators that is energy efficient). Penetration refers to flow and shows the fraction of sales, installation, or new construction of a certain type. For example, the penetration of high-efficiency room air conditioners might be $30 \%$ this year (referring to the new units sold), while the saturation of high-efficiency units is only $6 \%$ (referring to the units in use).

Table 7 shows a hypothetical example of the eligible market for a high-efficiencyrefrigerator program that targets all new refrigerators, early replacement of older refrigerators, and early retirement of secondary refrigerators. The eligible market for this particular year is 165,000 . The eligible market for the following year will change to reflect the number of early replacements and early retirements as well as the number of new refrigerators expected to be purchased for new homes.

Table 7. Calculation of eligible market for hypothetical high-efficiency refrigerator program

Market type

Number of

units

Total market (300,000 households):

Primary refrigerators

300,000

Secondary refrigerators

75,000

Eligible market:

Normal replacements (assumes a 20-year life)

18,750

Early replacements (primary refrigerators 15 to 20 years old)

56,250

Early retirements (all secondary refrigerators)

75,000

New units (purchased for new homes and additions to existing homes)

$\underline{15,000}$

Total eligible market:

165,000 


\section{TYPES OF MARKETS}

Programs typically deal with one or more of the following markets, which affect new and/or existing facilities: new construction, replacement, and retrofit. New-construction programs affect the design and construction of residential and commercial buildings and manufacturing facilities added to the stock each year. NORDAX (1990) considers all buildings that are in operation as of the beginning of the current year as existing. NORDAX defines new buildings as those constructed during the current year. The Wisconsin PSC (1990) and Massachusetts DPU (1989) do not differentiate clearly between these types of markets for reporting purposes. For some programs, the existing market should include those buildings in existence at the time of program initiation.

Table 8 shows how differences in definitions of housing stock can affect the participation rate. In this example, a weatherization program targets older homes with wall insulation of R-19 or less. New homes are being built with R-30 or greater and are therefore not eligible. After five years of the program, the NORDAX-type definition of existing homes results in a $41 \%$ cumulative participation rate while the other definition results in a $58 \%$ rate. This hypothetical, but realistic, example shows that the NORDAX definition would produce much lower estimates of participation rates by including new homes in the eligible category.

Programs for existing buildings affect replacements, retirements, additions, and retrofits. Replacement programs affect the efficiency of new equipment and systems bought to replace comparable equipment. Rebates for efficient residential appliances or for efficient lamps and ballasts are replacement programs. Normal replacement refers to replacement of worn-out (and perhaps obsolete) equipment. Early replacement is replacement of equipment before it reaches retirement age. In early retirement, the equipment is removed before it reaches retirement age but is not replaced (e.g., the elimination of second refrigerators). Existing buildings also have add-ons of new equipment not previously included in an existing building, such as the purchase of a food freezer for a home that previously had none. Finally, retrofit programs upgrade existing facilities and equipment, and may include early replacement of some equipment. Such programs encourage installation of additional insulation, caulking, weatherstripping, and storm windows and doors in residential structures.

Some applications may not fit easily into any of the above categories. For example, a commercial building may be totally gutted for remodeling. In this case, the resource costs and impacts of installing energy-efficiency or load-management options may be closer to those of new buildings than to those typical of existing buildings.

\section{PARTICIPATION RATES}

Participation rate is the ratio of the number of participating units to the number of units eligible to participate in the program. Each cf the different types of market potentia! 
has been used as the basis for program-participation-rate estimates, and each of these types of market potential may be defined differently. For example, NORDAX (1990) allows for slightly different definitions of "eligible market" depending on whether the total number of base technology units is known. The Wisconsin PSC (1990) requires utilities to report participation as both the percentage of market potential and the percentage of the total economic potential. The Massachusetts DPU (1989) defines participation rate as the percentage of the customer base, which for the residential sector is the number of buildings or dwelling units by dwelling type (e.g., single-family, multifamily, and mobile home). The customer base for the commercial sector is defined in terms of buildings or square feet by building type, while the customer base for the industrial sector is determined by the number of facilities in an SIC-code.

Table 8. Participation rates based on two definitions of existing homes

\begin{tabular}{lrrr}
\multicolumn{4}{c}{ Year } \\
\hline 1 & 3 & 4 & 5
\end{tabular}

Case 1: The number of existing homes is increased each year to include new homes constructed during the previous year

$\begin{array}{lcccrr}\text { Existing Homes } & 100,000 & 110,000 & 120,000 & 130,000 & 140,000 \\ \begin{array}{l}\text { New Homes } \\ \text { Incremental }\end{array} & 10,000 & 10,000 & 10,000 & 10,000 & 10,000 \\ \quad & & & & \\ \text { participants } & 5,000 & 7,500 & 10,000 & 15,000 & 20,000 \\ \text { Cumulative Participant: } & 5,000 & 12,500 & 22,500 & 37,500 & 57,500 \\ \% \text { of existing homes } & 5 \% & 11 \% & 19 \% & 29 \% & 41 \%\end{array}$

Case 2: The new homes in each period are not added to existing stock

\begin{tabular}{lrrrrr} 
Existing Homes & 100,000 & 100,000 & 100,000 & 100,000 & 100,000 \\
$\begin{array}{l}\text { New Homes } \\
\text { Incremental }\end{array}$ & 10,000 & 20,000 & 30,000 & 40,000 & 50,000 \\
$\quad$ & & & & \\
participants & 5,000 & 7,500 & 10,000 & 15,000 & 20,000 \\
Cumulative Participants & 5,000 & 12,500 & 22,500 & 37,500 & 57,500 \\
$\%$ of existing homes & $5 \%$ & $13 \%$ & $23 \%$ & $38 \%$ & $58 \%$ \\
\hline
\end{tabular}

Differentiating between the eligible and target markets can be confusing for programs that target multifamily buildings. For example, Con Edison has a program to encourage submetering in multifamily residential programs. Although all multifamily buildings are eligible, the target market is co-ops. Because landlords will not directly benefit from the program, they are not expecterl to be interested in participating. Because a small fraction of the landlords may participate anyway, it would be inappropriate to use the target market 
as a base for calculating participation rates. The eligible market is a better choice, although in this case it may be useful to report participation rate both as a percentage of the eligible market and as a percentage of the target market.

Table 9 illustrates the difficulty in comparing program participation rates. In some cases, the reporting utility defined the target market as the total number of customers in that sector. In other cases, the eligible market was defined as a subset of the total customer class. Although the eligible market or the target market base may be the most appropriate base for calculating participation rates, for reasons of consistency, reporting the participation rate as a percentage of the customer class may be more reasonable if the utility does not know the size of the eligible market.

The cumulative participation rate in a lighting program run by the Sacramento Municipal Utility District was variously calculated as $25 \%, 47 \%$, or $58 \%$ (Krause, Vine, and Gandh: 1989). The $25 \%$ rate was based on the number of customers in the targeted rate class, the $47 \%$ rate was based on the number of customers who were informed about the program, and the $58 \%$ rate was based on the number of customers who were eligible for the program as determined from the onsite lighting audits.

Table 9. Participation in utility residential new-construction programs

\begin{tabular}{lcccc}
\hline Utility & $\begin{array}{c}\text { Program } \\
\text { duration } \\
\text { (months) }\end{array}$ & $\begin{array}{c}\text { Number } \\
\text { of } \\
\text { participants }\end{array}$ & $\begin{array}{c}\text { Cumulative }^{\mathrm{a}} \\
\text { participation } \\
\text { rate }\end{array}$ & $\begin{array}{c}\text { Annualized } \\
\text { participation } \\
\text { rate }\end{array}$ \\
\hline City of Austin & 72 & 2,838 & $48 \%$ & $8 \%$ \\
Bonneville Power Administration & 72 & 8,976 & $17 \%$ & $3 \%$ \\
Caroina Power \& Light & 120 & 98,000 & $13 \%$ c & $2 \%$ \\
Duke Power & 36 & 4,600 & $15 \%$ & $5 \%$ \\
Florida Power & 48 & 12,416 & $39 \%$ & $10 \%$ \\
Pacific Gas \& Electric & 60 & 42,200 & $37 \%$ & $8 \%$ \\
Salt River Project & 96 & 47,589 & $60 \%$ & $8 \%$ \\
Sacramento Municipal & & & & $3 \%$ \\
$\quad$ Utility District & 36 & 4,165 & $9 \%$ & $3 \%$ \\
Tennessee Valley Authority & 96 & 31,000 & $26 \%$ & $5 \%$ \\
Virginia Power & 96 & 80,400 & $39 \%$ & \\
\hline
\end{tabular}

${ }^{a}$ Cumulative participation rate is the ratio of the number of participants to the number of eligible customers unless otherwise specified.

${ }^{b}$ Cumulative participation rate divided by number of years program exists.

'Carolina Power \& Light's participation rate is based on all residential customers.

Source: Sabo and Birnbaum (1990). 
The reporting utility should explain the assumptions used to define the eligible market. The descriptive information should also discuss the key factors that affect participation. These factors may include installed cost, operating costs, program design, program duration, typical payback, customer and trade ally awareness of the program, attributes of the technology (maturity, turnover, reliability), customer preferences and attitudes, design and installation difficulty, existing market penetration, potential for bill savings, and characteristics of the service area.

\section{TIME PERIODS}

Participation rates can be reported on an annual or cumulative basis. The annual participation rate is the ratio of the number of participating units in a particular year to the number of eligible units. The cumulative participation rate is the ratio of the number of participating units since the program began to the number of eligible units.

For most DSM programs, participation is essentially permanent. For example, it is unlikely that a customer will rip out insulation installed as part of a utility DSM programs. For some programs, such as interruptible rates, participation requires a periodic decision, such as renewal of a contract. For such programs, utilities sometimes report repeats, dropouts, and new participants:

Repeats: Customers who continue to participate in the program from the prior year Dropouts: Customers who do not renew their contracts

New participants: Customers who have not previously participated

Table 10 shows an example of such a program. Annual participation for a particular year indicates the number of participants who are enrolled in a particular program for that year, equal to the number of repeats plus the number of new participants. Incremental participation is the number of annual participants in the current year minus the annual participants in the previous year (also equal to the number of new participants minus the number of dropouts).

Pacific Gas and Electric (1991) reports repeats, dropouts, and new participants for time-of-use rates, interruptible rates, and other such programs. This kind of accounting is important and appropriate only for programs where it is possible to discontinue participation in a program or participation must be reaffirmed regularly.

The combination of these three groups of participants makes it difficult to report and interpret incremental or cumulative participation for interruptible-rate programs. The Massachusetts DPU (1989) defines incremental customers in these types of programs as "new" customers that are "associated with the incremental annualized savings" reported in that year. Massachusetts further specifies that participants in a one-year interruptible-rate program would be considered incremental new customers for each year the contract is renewed. 
Table 10. Example of data on participants for a load-management program

\begin{tabular}{|c|c|c|c|c|c|}
\hline $\begin{array}{l}\text { Year } \\
(t)\end{array}$ & $\begin{array}{l}\text { Repeats } \\
\text { (a) }\end{array}$ & $\begin{array}{l}\text { Dropouts } \\
\text { (b) }= \\
d_{t-1}-a_{t}\end{array}$ & $\begin{array}{l}\text { New } \\
\text { (c) }\end{array}$ & $\begin{array}{l}\text { Annual } \\
\text { participants } \\
(\mathrm{d})=\mathrm{a}_{\mathbf{1}}+\mathrm{c}_{\mathrm{t}}\end{array}$ & $\begin{array}{l}\text { Incremental } \\
\text { participants } \\
\text { (e) }=\mathrm{d}_{\mathrm{t}}-\mathrm{d}_{\mathrm{t}-1}\end{array}$ \\
\hline 1 & 0 & 0 & 100 & 100 & 100 \\
\hline 2 & 80 & 20 & 50 & 130 & 30 \\
\hline 3 & 75 & 55 & 50 & 125 & -5 \\
\hline 4 & 90 & 35 & 50 & 140 & 15 \\
\hline 5 & 110 & 30 & 70 & 180 & 40 \\
\hline
\end{tabular}




\section{ENERGY AND LOAD EFFECTS}

\section{INTRODUCTION}

The primary purpose of almost all utility DSM programs is to affect the level, efficiency, and timing of electricity use, the subject of this chapter. Therefore, it is essential that these terms be defined carefully. DSM programs often have other objectives, including improvements in customer service and satisfaction and the general well being of the service area (e.g., environmental improvements and economic development); these nonenergy effects are not discussed here.

\section{GROSS VERSUS NET EFFECTS}

The gross effect (savings for efficiency programs and increases for load-building programs) is the change in electricity use experienced by participants in a DSM program. The net effect is the portion of the gross effect that can be directly attributed to the program. (Gross savings is sometimes referred to as total savings, and net savings is sometimes referred to as program savings.) Thus, net savings is the difference between gross savings and the changes in participant electricity use that would have occurred had the utility program not existed. A comparison group is often used to estimate what participants would have done in the absence of a program.

The ratio of net to gross effects is sometimes greater than one and sometimes less than one. If electricity prices are declining and the economy is growing, electricity use without the program might increase. In such cases, net savings will be greater than gross savings (Fig. 5). On the other hand, if prices are rising, customers will be motivated to improve efficiency without utility programs; in such cases, net savings will be less than gross savings (as shown in Fig. 6 for a residential retrofit program). The Fig. 6 estimates of gross and net savings were based on analysis of monthly electricity bills for samples of nonparticipants and program participants in the Bonneville Power Administration (BPA) residential retrofit program (Hirst et al. 1985). The reductions in electricity use for nonparticipants were stimulated primarily by rapidly rising electricity prices during the early 1980s. During the mid- and late 1980s, the situation reversed. During this later period, electricity prices were stable, and incomes were rising. As a consequence, net savings were greater than gross savings. For example, participants in the BPA program in 1986 had a gross savings of $2200 \mathrm{kWh} /$ year, but a net savings of $2800 \mathrm{kWh} /$ year (Schweitzer, Brown, and White 1989). 


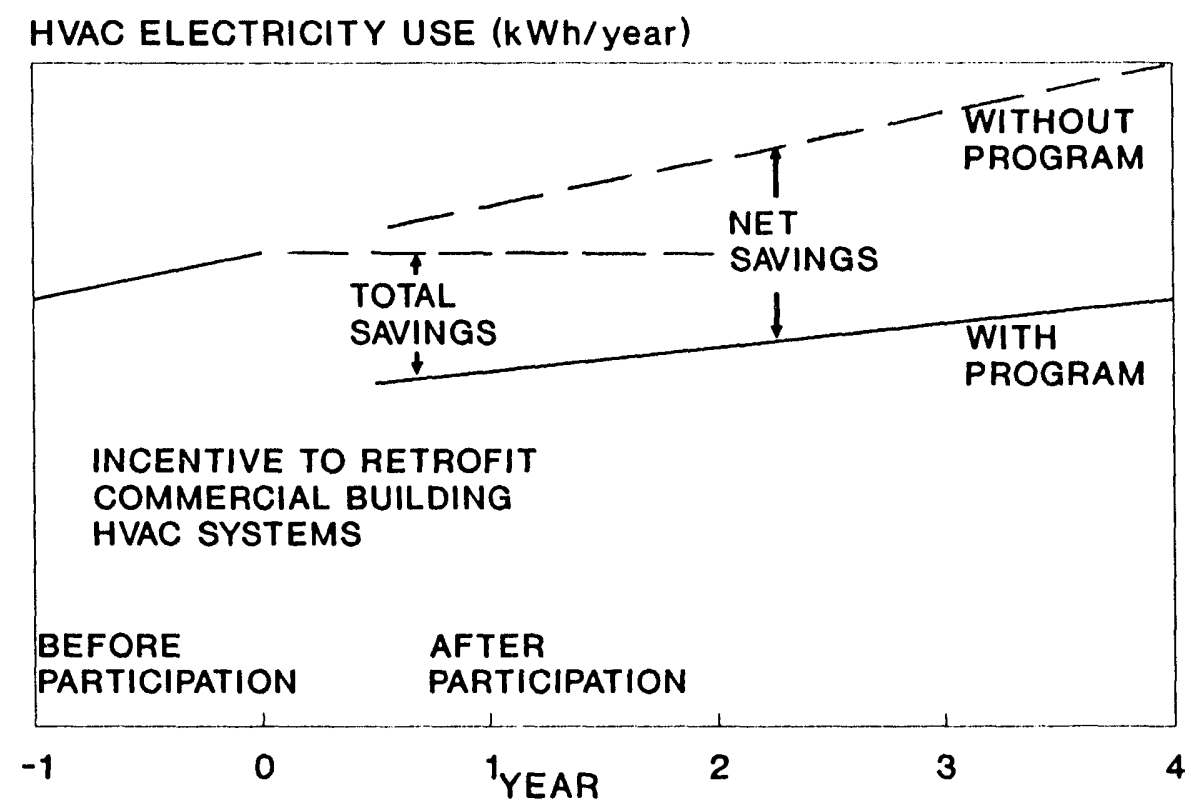

Fig. 5. Schematic of electricity use per participant for commercial buildings with and without utility program aimed at improving HVAC systems. Electricity use is increasing in response to declining electricity prices and a growing economy.

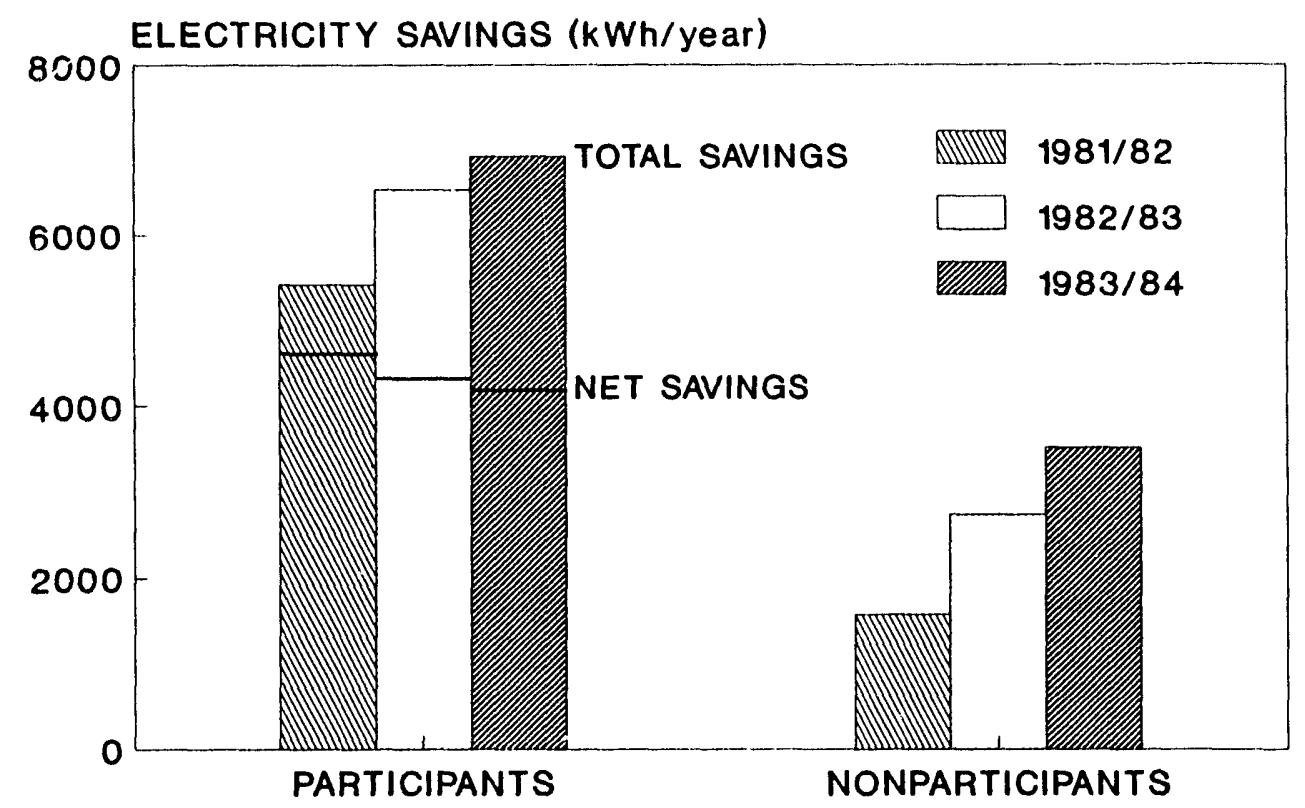

Fig. 6. Gross and net electricity savings for participants in the BPA pilot Residential Weatherization Program. Although gross savings increased with time, net savings decreased because of increases in electricity prices. 
Various factors affect the differences between net and gross effects. Free riders refers to customers that participate in a program but would have adopted the program recommendations anyway. Any energy savings or load reductions achieved by these customers do not contribute to net savings, although the costs of providing services to these customers are considered program costs. Free ridership can occur for all types of DSM programs. For an appliance rebate program, free riders are households that would have purchased a qualifying appliance without the program and that still apply for the rebate. For a load control program, free riders are participating households that do not normally use the controlled equipment during control periods (e.g., households that are not at home during the day and have their air conditioners turned off during those times).

There are at least three different types of free riders: complete, partial, and delayed. Complete free riders are customers who would have adopted fully the utility recommendations. Partial free riders are customers who would have adopted only some of the recommendations without the program or would have purchased equipment or appliances that are more efficient than the average but less than the program promotes. And delayed free riders are customers who would have adopted some or all of these recommendations, but only some time in the future.

Free drivers, on the other hand, are customers that do not participate in a program but are influenced by the program and adopt program recommendations anyway. Although these customers contribute nothing to the utility cost of the program, the savings or load reductions they experience should be credited to the program and included in net savings. For example, appliance dealers may stock efficient appliances because of a utility rebate program. Some customers may purchase these high-efficiency units but not apply for the utility rebate; these customers are free drivers. DSM programs that aim to transform the market implicitly seek to make everyone a free driver.

Figure 7 illustrates the effects of free riders and free drivers for a hypothetical utility program. This program offers rebates for the purchase of high-efficiency air conditioners [with an energy-efficiency ratio (EER) above 9.0]. The smooth curve shows the distribution of EER for new purchases without the program. (This distribution could be based on data collected before the utility program began or on sales in a neighboring area where the program is not offered.) Note that some customers purchase high-efficiency units without the program. The curve with the discontinuity at EER $=9$ shows the distribution after the program is in place. The discontinuity occurs because people who would have bought an air conditioner with an EER slightly below 9 are quite likely to shift at least slightly and buy a qualifying unit with an EER above 9. The cross-hatched area shows the customers that participated in the utility's program. Some of these participating customers would have purchased these high-efficiency units without the program and are free riders. On the other hand, some customers who would not have purchased high-efficiency units without the program did purchase such units, but did not request rebates from the utility; these customers are free drivers. Thus, customers who purchased qualifying units fall into one of four groups: (a) customers who would have purchased such units without the program and did not request the utility rebate, (b) customers who would have purchased such units 
without the program and did request the utility rebate (free riders), (c) customers who would not have purchased such units without the program and did request the utility rebate, and (d) customers who would not have purchased such units without the program and did not request the utility rebate (free drivers). Groups $b$ and $c$ are program participants.

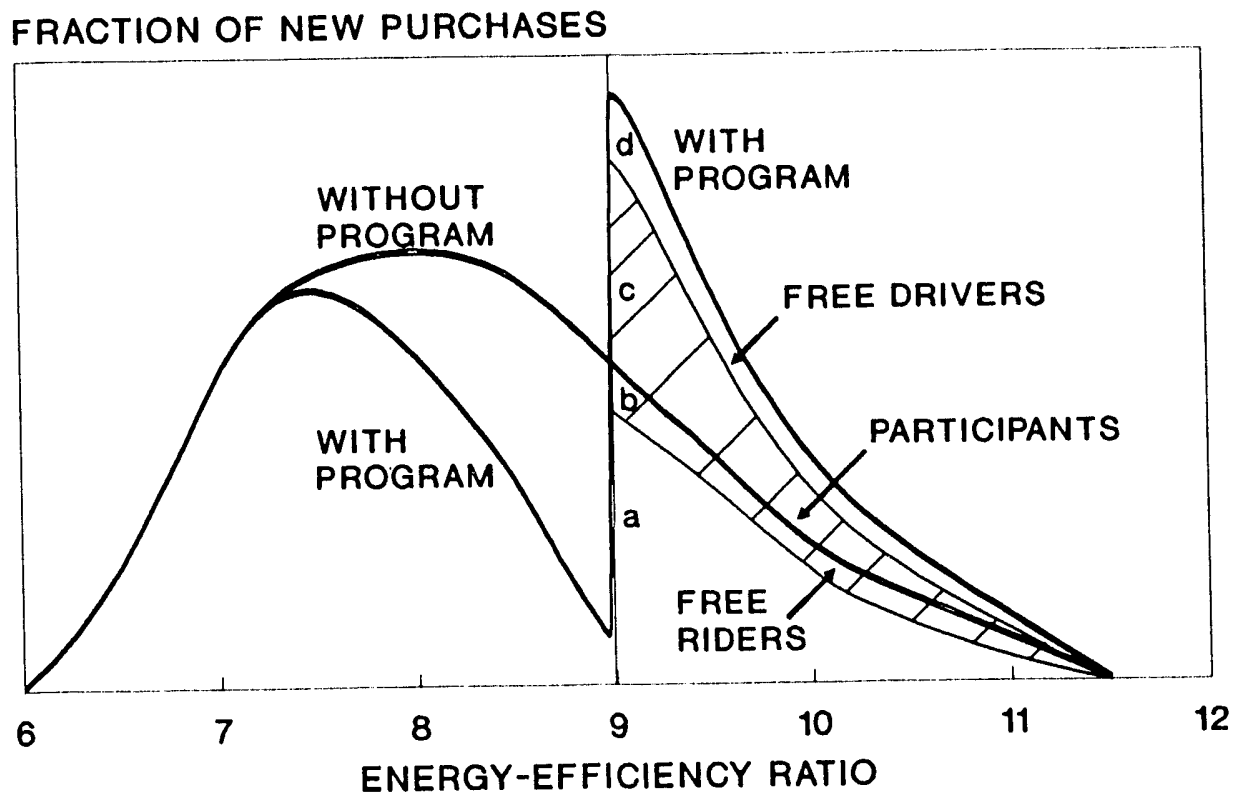

Fig. 7. Hypothetical distributions of energy-efficiency ratio for new air conditioners with and without utility program. The groups $a, b, c$, and $d$ are defined in the text.

If customers change the energy-related operating practices of their facility as a consequence of participating in a DSM program, the effect is called takeback (sometimes called rebound or snapback). Takeback, in essence, refers to the difference between changes in energy efficiency and energy use. For example, a household that increases its use of the air conditic-er after the utility helps pay for a new, more energy-efficient unit, will experience smaller energy and load reductions than initially expected. This type of response to the lower operating cost of a more efficient unit is consistent with economic theory as reflected in estimates of own-price elasticity. Consider an industrial customer that makes energy-efficiency improvements through a utility DSM program. If this company expands production (which, in turn, increases electricity use) because of the lower operating costs associated with the program-induced efficiency improvements, this too is a form of takeback. Although takeback reduces the measured energy savings, it is a benefit to customers (e.g., greater comfort or higher productivity). 
These, and perhaps other, factors help to explain differences between net and gross savings. In many cases, it is not necessary - and perhaps not possible! - to disaggregate the difference between net and gross savings into its components. It is not necessary because these factors are subsumed within the definitions of net and gross savings. (However, these factors are important in program planning and modification.) And it may not be possible to identify the effects of these factors because of their subtlety and complexity. For the purposes of this handbook, we focus on net and gross effects and do not address explicitly these contributing factors.

Although the importance of free riders (Saxonis 1989; Violette et al. 1991) and takeback (Khazzoom 1987; Henly, Ruderman, and Levine 1988) has been hotly debated, little empirical evidence exists on these factors. Dinan and Trumble (1989) showed that there was only a very small increase in wintertime indoor temperatures after retrofit in the Hood River Conservation Project. And Greene (1991) showed that improving automobile fuel economy has only a slight effect on increasing the number of miles traveled.

\section{TEMPORAL DIMENSIONS OF EFFECTS}

Three temporal issues are important to utilities for their DSM programs. The first concerns changes in load shapes, the second concerns differences between annual and cumulative energy effects, and the third concerns long-term persistence of changes in electricity use.

Load-Shape Changes. As discussed in Chapter 2, utilities have different objectives for their DSM programs. Some programs affect overall energy use (expressed in $\mathrm{kWh} /$ year); these energy effects refer to the changes in aggregate electricity use for customers that participate in a DSM program. In addition, utilities are also interested in changes at the times of winter and summer peaks $(\mathrm{kW})$, class peaks $(\mathrm{kW})$, and the overall load shape (e.g.. 24-hour load shape or full 8760-hour annual load shape). Thus, there are several dimensions to changes in electricity use.

Figure 8 illustrates these time-of-use effects for residential electric water heating. The Hood River Conservation Project paid for installation of water-heater wraps, pipe wraps, and low-flow showerheads for homes that used electricity for water heating in Hood River, Oregon (Brown, White, and Purucker 1987; White, Tonn, and Stovall 1991). The figure shows diversified 24-hour load shapes for typical winter weekdays for 145 homes: loads before retrofit (1984/85), loads after retrofit (1985/86), and reductions in loads between the two years. Diversified demand refers to the average load across a group of customers. Load shapes for individual customers are erratic as equipment is turned on and off. However, when averaged across a large number of similar customers, the load shape assumes a pattern that is consistent for different days and seasons. Thus, Fig. 8 shows the hourly loads (in $\mathrm{kW} /$ home) averaged across the 145 homes, all of which had electric water heaters retrofit by the program. 
Load shapes and, perhaps more important, peak loads differ across different types of customers. For example, residential loads peak earlier on winter weekdays (when people get up, cook breakfast, and take showers) than do commercial-building loads (which peak when people arrive at work and turn on lights and office equipment). Such differences are reflected in differences in the size and timing of class peak loads (sometimes called noncoincident peak loads). Typically, these class loads refer to the maximum loads imposed by residential, commercial, or industrial customers. The system peak demand refers to the maximum total load on the utility's electric system. Figure 8 illustrates some of these differences. The residential water-heating class peak occurs at $8 \mathrm{am}$, while the utility system peak occurs at 9 am. However, the greatest reduction in load caused by the water-heating retrofit measures occurs at 7 am. Perhaps the most important measure for a utility is the reduction in diversified demand at the time of system peak $(0.08 \mathrm{~kW} /$ household at 9 am in this example), called the diversified coincident peak demand effect.

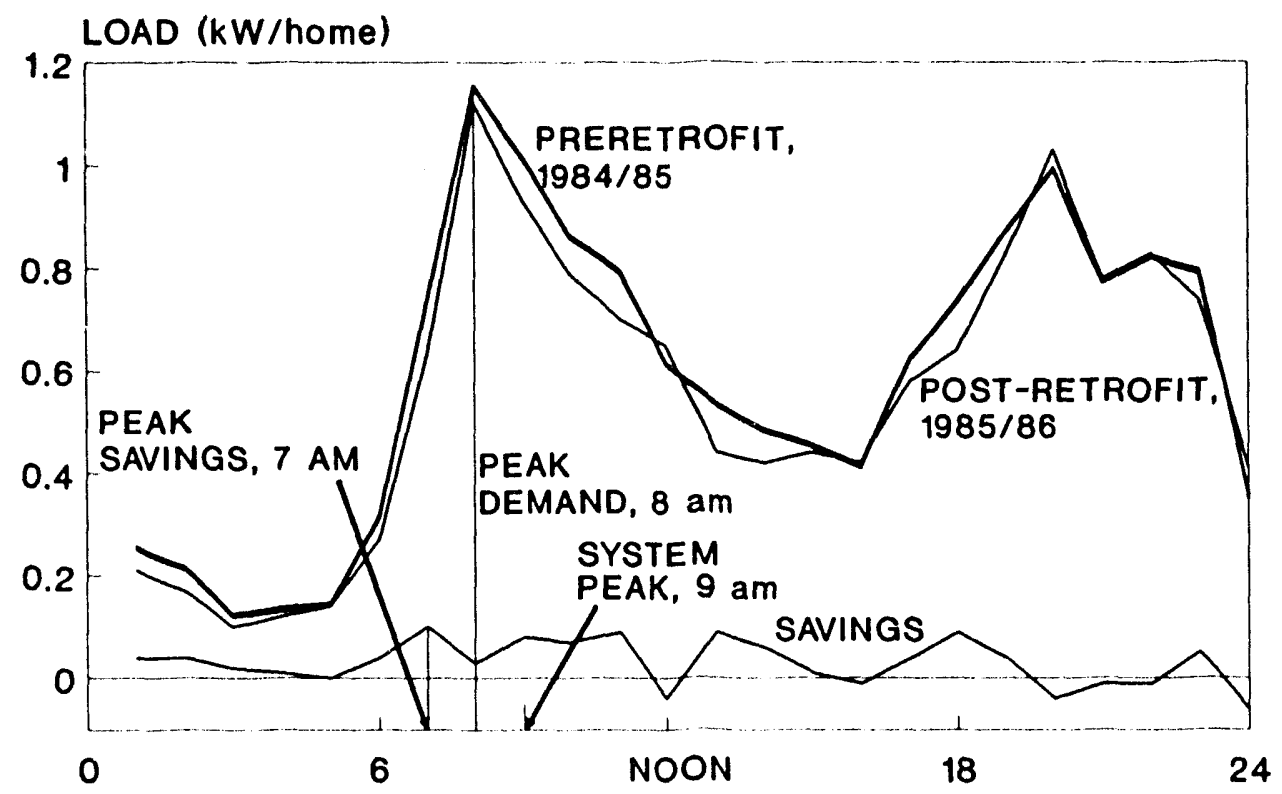

Fig. 8. Diversified 24-hour winter weekday load-shapes for electric water heating in 145 Hood River, Oregon, homes.

Different electric end uses have different load shapes, which vary from season to season. For example, household use of clothes dryers, ranges, and water heaters contribute more to system peaks in winter than in summer in Massachusetts; the reverse is true for refrigerators (Table 11). The coincidence factor (ratio of appliance demand at the time of system peak to the appliance peak demand) also varies across end uses and is higher for refrigerators and water heaters (which are nearly baseload appliances) than for clothes dryers or ranges (which are used only intermittently). In California, air conditioning loads 
in commercial buildings are essentially coincident with utiliiy system peaks (California Energy Commission 1990).

Table 11. Electricity use and diversified loads for residential appliances

\begin{tabular}{lrrrr}
\hline & $\begin{array}{c}\text { Clothes } \\
\text { dryer }\end{array}$ & $\begin{array}{r}\text { Refrig- } \\
\text { erator }\end{array}$ & Range & $\begin{array}{r}\text { Water } \\
\text { heater }\end{array}$ \\
\hline $\begin{array}{l}\text { Annual use (kWh) } \\
\text { Demand at time of }\end{array}$ & 852 & 2008 & 478 & 3575 \\
$\begin{array}{l}\text { system peak (kW) } \\
\text { Peak season }\end{array}$ & 0.97 & 0.34 & 0.70 & 1.70 \\
Noncoincident peak (kW) & Winter & $\begin{array}{r}\text { Summer } \\
0.53\end{array}$ & $\begin{array}{r}\text { Winter } \\
3.45\end{array}$ & $\begin{array}{r}\text { Winter } \\
4.07\end{array}$ \\
\hline
\end{tabular}

Source: Massachusetts Joint Utility Monitoring Project (Fitzpatrick 1991).

Annual and cumulative effects. The changes in annual energy (in GWh/year) caused by a utility program can refer either to the annual effects caused by the program's activities in the current year or to the cumulative effects caused by the program's activities since its inception. Figure 9 illustrates these concepts for a program that runs for three years. The energy savings caused by customers who participate in the first year slowly declines (presumably because of takeback and other factors related to equipment performance). After ten years, the equipment wears out so that in year 15 there are no longer any savings associated with these first-year participants. Similar sequences of savings occur for participants in years 2 and 3 . The top (heavy) curve shows the cumulative savings caused by this program, the sum of the savings associated with the participants from all the years the program operated. Clearly, it is important to identify the savings as either annual or cumulative when reporting results. A third measure of energy effect, called integrated effects, refers to the sum of the cumulative effects for each year of the program (i.e., the area under the curve of Fig. 9).

A complication occurs for programs that begin or end during a year (rather than on January 1). The energy effects for such part-year periods should be reported on an annualized basis (GWh/year) for that period. Another complication occurs because not all customers participate on January 1 . For a particular program year, participants in December contribute smaller savings than do January participants. Given the uncertainties about estimated electricity savings, the results could be reported on an annualized basis as if all participation during a particular calendar year occurred on July 1. Regardiess of how annual energy effects are computed for a particular year, that method must be consistent with the methods used to compute and report program participation and program costs. 
NET ENERGY SAVINGS (GWh/year)

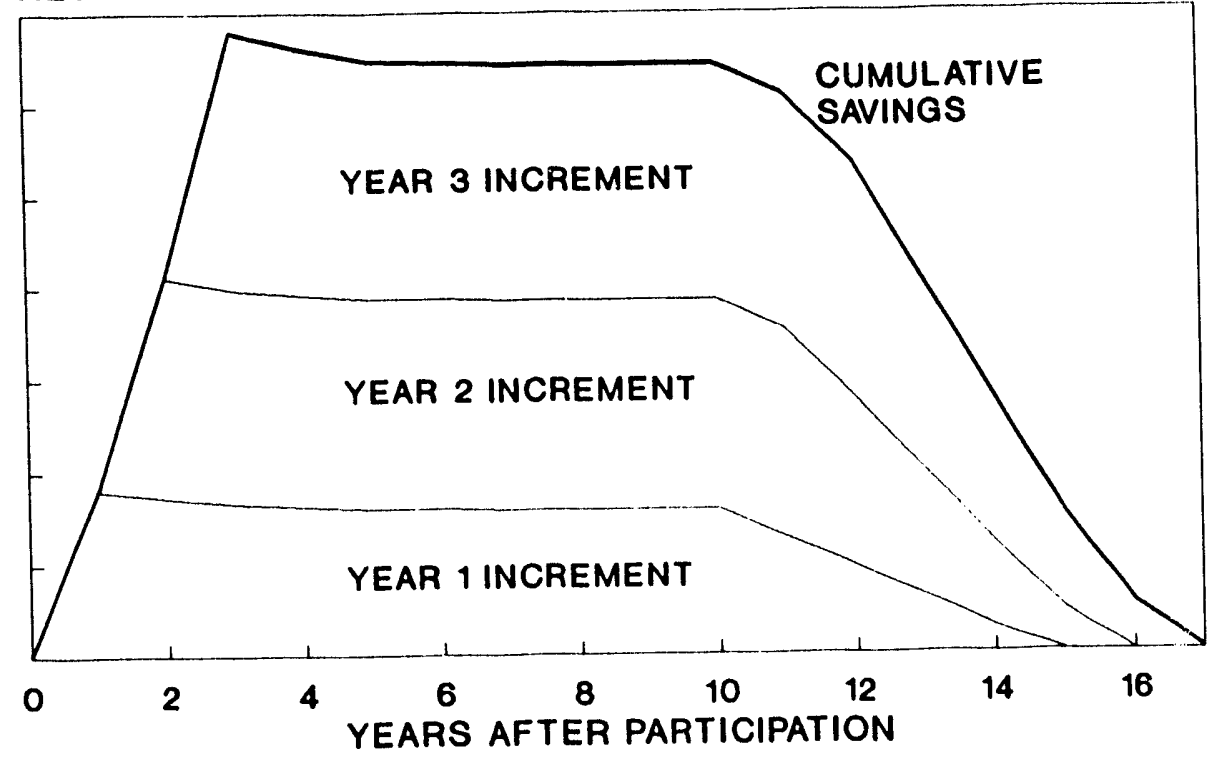

Fig. 9. Differences among annual, cumulative, and integrated electricity savings caused by a utility DSM program.

Long-term persistence of effects. The curves in Fig. 9 show small declines for several years after participation. These declines reflect changes in the technical performance of DSMprogram measures, the lifetime of measures, user replacement of measures when they wear out, operational changes induced by the DSM program, and market-induced changes in electricity use. Persistence has dimensions that affect both gross and net effects. The net savings for the residential retrofit program run by Seattle City Light (Sumi and Coates 1989) declined slowly from 1982 through 1987 primarily because of increases in electricity prices (which encouraged nonparticipants to adopt measures that participants had adopted earlier).

In essence, the combined effect of the factors discussed here yields the lifetime of the programmatic energy effects. This lifetime, while related to the physical lifetimes of the measures installed, includes many other factors. Utilities often calculate the lifetimes of programmatic effects as the sum of the weighted lifetimes of the individual measures installed by a program, where the weights are the estimated electricity savings for each measure. Unfortunately, this approach captures only the technical aspects of programmatic lifetime and ignores the behavioral aspects.

\section{DATA AND ANALYSIS METHODS}

Two issues are important here. One concerns the types of data collected to measure electricity use. The verb measure refers to collection of data on electricity use. The second 
issue concerns the analytical approaches used to estimate gross and net effects (both energy and demand). The verb estimate refers to the analytical procedures applied to the data to compute electricity and load changes.

Types of data. Measurements of electricity use can be based on customer monthly electricity bills, special short-term metering (e.g., a few weeks of $\mathrm{kW}$-demand measurements bcfore and after retrofit), whole-building load-research data, or end-use load monitoring (i.e., time-ofuse measurements of electricity use by end use); see Table 12. As the cost and complexity of data collection grows, it becomes infeasible to collect data for all the program participants. Hence, sampling procedures, especially for load-research data, are critical to data quality and relevance as well as to cost control.

In some cases, measuring the savings is not necessary. This would be the case for a DSM program that focuses on a few simple measures with which utilities have substantial experience, for which savings are largely invariant across customers and utilities, and for which savings have been measured in the past. In such cases, past measurements and engineering calculations can be relied on to estimate savings for the program. At the other end of the spectrum, where a program includes a variety of actions, the installation of which depends on the individual circumstances at each customer facility (e.g., retrofit of the envelope for large commerciai buildings), site-specific measurements of specific end-use load-shapes may be the best way to estimate saved electricity.

Monthly electricity bills for both participating and nonparticipating customers are probably the most straightforward and least expensive data to use in measuring program effects. Typically, such records would be collected for at least a year before participation and a year after participation. For programs aimed at new construction, billing data would be collected for samples of new buildings that participated in the program and new buildings that did not. Analysis of the billing data might account for changes in winter and summer severity to correct for year-to-year variations in electricity use for space heating and air conditioning. If data on the facility, its operations, and its occupants are available, the analysis might also account for changes in hours of use, for changes in electricity-using equipment, and so on. This approach is well suited for residential and small commercial buildings, where the effects of outdoor temperatures are important determinants of electricity use for heating and air conditioning.

If a program affects cnly some electricity end uses in a facility, it might not be possible to observe the savings at the whole-building level; the signal-to-noise ratio in monthly electricity bills may be too low to detect the savings. For example, water heating accounts for about $5 \%$ of the electricity use in a typical office building. Cutting electricity use for water heating by $20 \%$ will reduce electricity use by only $1 \%$, a savings that could easily be overwhelmed by normal fluctuations in total electricity use. In such cases, end-use metering, while much more expensive than reliance on billing data, may be necessary to identify the actual savings. Such metering, because it records time-of-use (e.g., hourly) information is also important when the benefits of a program depend on the timing of 
savings. For example, a winter-peaking utility will value a $\mathrm{kWh}$ saved on a January morning more than a $\mathrm{kWh}$ saved in spring, summer, or fall.

Table 12. Methods used to measure electricity consumption

\begin{tabular}{|c|c|c|c|}
\hline Approach & Explanation & Advantages & Disadvantages \\
\hline $\begin{array}{l}\text { Monthly } \\
\text { electricity bills }\end{array}$ & $\begin{array}{l}\text { Obtain electricity bills for } \\
\text { a year before and a year } \\
\text { after participation, adjust } \\
\text { annual electricity use for } \\
\text { weather and other } \\
\text { relevant factors, and } \\
\text { computc the difference } \\
\text { between pre- and post- } \\
\text { participation use in } \\
\mathrm{kWh} / \text { year. }\end{array}$ & $\begin{array}{l}\text { Measures actual changes } \\
\text { in electricity use, permits } \\
\text { adjustment for changes in } \\
\text { weather and other factors, } \\
\text { and requires little primary } \\
\text { data collection. }\end{array}$ & $\begin{array}{l}\text { Provides no estimate of } \\
\text { demand (kW) reductions } \\
\text { unless customers face } \\
\text { demand charges. Analysis } \\
\text { of monthly billing data } \\
\text { can yicld ambiguous } \\
\text { results. Estimates of } \mathrm{kWh} \\
\text { savings affected by } \\
\text { changes in facility use } \\
\text { unrelated to devices } \\
\text { installed. }\end{array}$ \\
\hline $\begin{array}{l}\text { Spot metering } \\
\text { of electricity use }\end{array}$ & $\begin{array}{l}\text { Monitor electricity use } \\
\text { before and after } \\
\text { participation for short } \\
\text { times (e.g., a few days); } \\
\text { also measure other } \\
\text { relevant factors (e.g., } \\
\text { operating hours for } \\
\text { equipment and heating } \\
\text { degree days) for a longer } \\
\text { time (e.g., up to a year). }\end{array}$ & $\begin{array}{l}\text { Measures electricity } \\
\text { savings (both } \mathrm{kWh} \text { and } \\
\mathrm{kW} \text { ) for well-defined, } \\
\text { short time periods. } \\
\text { Modest cost. }\end{array}$ & $\begin{array}{l}\text { Could yield estimates of } \\
\text { savings not realized if } \\
\text { measurements taken } \\
\text { incorrectly or at atypical } \\
\text { times, or if building use } \\
\text { changes. Difficult to } \\
\text { apply to devices that are } \\
\text { season- or weather- } \\
\text { dependent. }\end{array}$ \\
\hline $\begin{array}{l}\text { Whole-building } \\
\text { load-research } \\
\text { monitoring }\end{array}$ & $\begin{array}{l}\text { Monitor electricity use of } \\
\text { facility to record } \mathrm{kW} \\
\text { demand before and after } \\
\text { participation }\end{array}$ & $\begin{array}{l}\text { Measures actual } \\
\text { electricity use and } \\
\text { demand (kWh and } \mathrm{kW} \text { ). } \\
\text { Can be combined with } \\
\text { other data to adjust for } \\
\text { changes in weather and } \\
\text { other factors. }\end{array}$ & $\begin{array}{l}\text { Expensive and time } \\
\text { consuming. Large } \\
\text { amounts of data } \\
\text { produced. Results may be } \\
\text { affected by changes in } \\
\text { facility use unrelated to } \\
\text { equipment installed. }\end{array}$ \\
\hline $\begin{array}{l}\text { End-use, load- } \\
\text { research } \\
\text { monitoring }\end{array}$ & $\begin{array}{l}\text { Monitor specific circuits } \\
\text { affected by new systems } \\
\text { to record } \mathrm{kW} \text { demand } \\
\text { before and after } \\
\text { participation. }\end{array}$ & $\begin{array}{l}\text { Measures actual } \\
\text { electricity use and } \\
\text { demand ( } \mathrm{kWh} \text { and } \mathrm{kW} \text { ) } \\
\text { for specific end uses } \\
\text { affected by program. Can } \\
\text { be combined with other } \\
\text { data to adjust for changes } \\
\text { in weather and other } \\
\text { factors. }\end{array}$ & $\begin{array}{l}\text { Most expensive and time } \\
\text { consuming method. } \\
\text { Large amounts of data } \\
\text { require sophisticated } \\
\text { computer programs and } \\
\text { analysts to interpret. } \\
\text { Results may be affected } \\
\text { by changes in facility use } \\
\text { unrelated to equipment } \\
\text { installed. }\end{array}$ \\
\hline
\end{tabular}


$\mathrm{A} r$ intermediate method involves special, periodic measurements of electricity demand. This approach measures electricity demand (typically recorded at 30-minute intervals for 30 days) on circuits affected by the particular DSM actions taken. Boston Edison (1989) uses this method to estimate savings for lighting, motors, and HVAC controls in commercial buildings. Such measurements are taken at least twice, once before retrofit and once after retrofit. Monthly or annual electricity savings are then computed on the basis of the difference in pre- and post-retrofit electricity use, adjusted for the number of hours per month (or per year) that the system is in operation. This method is suited for large commercial buildings and industrial facilities, which often have regular operating schedules and use electricity for many different purposes.

Analytical Approaches. The methods used to analyze energy savings vary (Violette et al. 1991; Xenergy 1990); see Table 13. In many cases, it may be appropriate to combine different data sources and analytical techniques. Such hybrid methods, which might incorporate engineering and statistical methods, may yield estimates of energy savings and load reductions that are especially robust.

Engineering estimates of energy and load changes can be based on simple rules of thumb, on hand calculations that use manufacturer data, or on detailed engineeriig simulations that require considerable site-specific data. Unfortunately, evidence (Nadel and Keating 1991) indicates that engineering calculations typically yield estimates of electricity savings higher than achieved. However, for some DSM actions (e.g., insulation wrapped around a residential water heater), this approach can yield reliable estimates of energy savings. As the input data and assumptions used in these methods improve, the accuracy of this approach should likewise improve.

Analysis of monthly electricity bills can include adjustments for differences in heatingor cooling- degree days (Fels 1986). More sophisticated statistical analysis (e.g., conditional demand) adjusts for differences across customers and time in winter and summer temperatures, the structure and operating characteristics of the facility, and the economic and demographic characteristics of the facility occupants (Parti and Parti 1980; Train and Ignelzi 1987; Violette et al. 1991). End-use load data can be adjusted for weather or 'iy or analyzed with regression approaches to account for various factors affecting electricity use (Caves, Lowry, and Wharton 1989).

Data users and providers need to agree on the point in the electric system at which savings are measured. NEPLAN (1990b) collects electricity-saving estimates "at the customer (meter) level"; these estimates, therefore, do not include transmission- and distribution-system losses, nor do they include reserve margins. Such adjustments are needed to compare DSM resources with power plants and other supply resources. Identification of the long-term savings caused by DSM programs may require additional data collection and analysis on the lifetimes of the systems installed, their degradation with time, and the energyrelated behaviors of facility operators. Data on the electricity savings associated with certain technologies (and perhaps some programs) may be transferable from one utility to another. 
The cost savings associated with such data transfers are likely to be large where end-use load-monitoring data are involved.

Net effects are the difference between energy use (and load shape) that would have occurred without the program minus actual (post-participation) energy and loads. The second term can be measured with one of the methods discussed above, but the first term cannot be measured because it does not exist. The first term can only be inferred, based on measurements of energy and loads for a comparison group. The comparison group is usually either a similar group of nonparticipants or the participant group before participation. For example, in an appliance-rebate program, the comparison group might be a portion of the service area in which the program is not operated or a sample of residential customers who purchased new appliances from nonparticipating dealers. For a program aimed at improving efficiency of new construction, the comparison group might be a group of similar new buildings that did not participate in the program but that met local building codes. And for a program that offers an interruptible-rate program, the comparison group might be based on the load shapes of the participating customers on noncontrol days.

Table 13. Methods used to analyze data to estimate changes in electricity use

\begin{tabular}{|c|c|c|}
\hline Method & Strengths & Limitations \\
\hline $\begin{array}{l}\text { Transfer of data } \\
\text { from other utilities }\end{array}$ & $\begin{array}{l}\text { Easy to do } \\
\text { Low cost }\end{array}$ & $\begin{array}{l}\text { May not reflect conditions for } \\
\text { this program or this utility }\end{array}$ \\
\hline $\begin{array}{l}\text { Engineering } \\
\text { calculations }\end{array}$ & $\begin{array}{l}\text { Analyzes individual DSM } \\
\text { measures } \\
\text { Inexpensive unless extensive } \\
\text { data on facility, its equipment, } \\
\text { and operating schedules are } \\
\text { collected }\end{array}$ & $\begin{array}{l}\text { Does not address behavior } \\
\text { Based on many assumptions } \\
\text { Often overestimates actual } \\
\text { savings }\end{array}$ \\
\hline $\begin{array}{l}\text { Comparisons of } \\
\text { energy data }\end{array}$ & $\begin{array}{l}\text { Easy to do } \\
\text { Low cost } \\
\text { Standard methods for weather } \\
\text { normalization }\end{array}$ & $\begin{array}{l}\text { Does not provide demand } \\
\text { impacts } \\
\text { May not adequately correct for } \\
\text { nonweather determinants of } \\
\text { electricity use }\end{array}$ \\
\hline Statistical analysis & $\begin{array}{l}\text { Provides end-use details } \\
\text { Incorporates takeback and } \\
\text { free riders } \\
\text { Statistical basis shows } \\
\text { confidence intervals }\end{array}$ & $\begin{array}{l}\text { Substantial data requirements } \\
\text { on facility, its equipment, and } \\
\text { occupants } \\
\text { Multicolinearity often a } \\
\text { problem }\end{array}$ \\
\hline
\end{tabular}




\section{PROGRAM COSTS}

\section{INTRODUCTION}

The program-cost data that utilities report are often incomplete or not sufficiently detailed to use to compare or assess DSM-program performance. That trend is changing as program costs increase and utilities seek cost recovery and incentives through regulatory ratemaking.

Traditional utility accounting systems often do not provide the level of detail required for DSM program reporting, planning, and evaluation. DSM accounting requires systems that provide sufficient detail to distinguish the various types of program costs (Fig. 10). In addition, traditional accounting systems only monitor utility expenditures. Costs borne by the customer and other nonutility parties are often not provided by existing accounting systems. Knowledge of these costs is necessary for calculating program cost-effectiveness from the perspectives of participating customers and society. The Northwest Power Planning Council provides both utility and customer costs for installed conservation measures (Berry 1989). On the other hand, Central Maine Power Company's monthly energy conservation report provides detailed information on program costs from its accounting system, but does not include customer costs.

Comparing program cost information is difficult because utilities do not always:

- report the same types of costs in the same cost categories,

- include all costs associated with a particular cost category,

allocate common costs in the same manner, or

- use the same methods for estimating costs.

Utilities do not always report the same types of costs in the same cost categories. Blagden (1991) found that different utilities report different types of costs as DSM program costs. Program planning, development, and evaluation expenses may or may not be included in reported program costs. In addition, the same types of costs are not reported in the same categories. Berry (1989) examined variations in the ways that BPA conservation-program managers classified administrative costs. Different program managers were classifying a number of program-cost categories differently. Some costs were considered administrative by half of the managers and were considered nonadministrative by the other half. These 
costs included advertising, energy audits, computer-program development, staff training, and administrative payments to implementors.

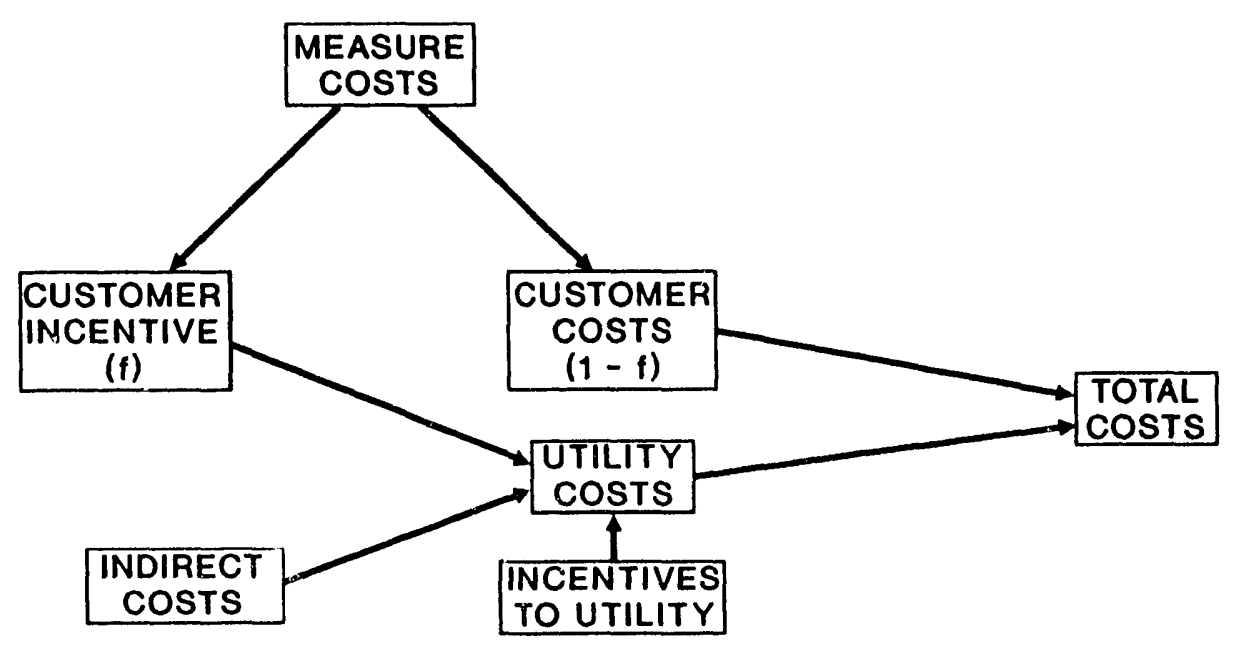

Fig. 10. Total DSM-program costs can be distributed in different ways. (The fraction of the cost of DSM measures paid by the utility is $f$.)

Utilities do not always include all costs associated with a particular cost category. Not all administration costs are always included in reported costs. Staff included in the rate base prior to program initiation may not be counted even though they may be working directly on DSM programs. Utilities are more likely to report incremental costs for the addition of new staff or equipment for DSM programs. In many cases, general, administrative, and other overhead costs not specific to the program are not captured even though they are necessary for the program.

Utilities do not always allocate common costs in the same manner. Common costs are those shared by a number of programs. Promotional materials and advertising often support more than one program. Direct mailings, bill stuffers, trade show displays, and media advertising may target a specific customer sector but affect several programs aimed at that sector. Thus, utilities often combine into one informational program such activities as toll-free hotlines, energy information centers, and major promotional efforts to publicize a number of technologies, measures, or programs. These costs often are not assigned to individual DSM programs.

Utilities do not always use the same methods for estimating costs. A number of methods can be used to determine the incremental cost of equipment. If an audit is 
conducted, equipment costs may be based on engineering estimates made at the time of the audit. In other cases, utilities record the actual installed cost of the equipment but estimate costs of the equipment that would have been installed in the absence of the program. For example, the actual cost of a specific high-efficiency air conditioner may be compared to the average cost of air conditioners being sold today.

\section{LEVEL OF DETAIL}

The level of detail and number of categories of program costs reported by utilities vary widely. A number of factors affect the level of reporting, including the sophistication of the accounting system used to collect program costs, the frequency of reporting, and the users of the information. Program cost information appears in a number of sources:

- Annual status reports summarizing the accomplishments of the DSM programs

- Monthly or quarterly progress reports for program tracking and cost recovery

- Summary data for inputs to cost-effectiveness models

- Planning studies for power pools

- Reporting forms required by government agencies

- Research organizations' surveys of utility programs

- Databases developed through collaborative efforts

The level of detail reported is often driven by regulatory requirements. Although Central Maine Power Company's accounting system reports very detailed information monthly, EIA (1990) and NEPLAN (1990b) require utilities to report only total cost for a program. In May 1990, the New York utilities filed a proposed common accounting method for reporting DSM program costs to the New York DPS (1990b) in a consistent manner (Table 14).

The level of detail reported by a utility should be sufficient to support a number of different functions, including program evaluation, analysis of program cost-effectiveness, design of new programs, budgeting of program expenditures, and justification for regulatory cost recovery. Program costs used for these purposes can be grouped in a few broad categories (Table 15).

Some of the costs that third parties or customers incur may be reimbursed by the utility. Guarding against double-counting of costs is therefore important.

Utilities should report the portion of equipment costs paid by the utility. These costs are classified as equipment costs if the utility purchases the equipment directly. These costs 
are considered incentives if rebates are offered to help defray the costs of equipment purchased by the customer.

Table 14. Common accounting method used by New York utilities to report DSM costs

Labor

Gross wages

Salaries

Overtime

Employee benefits

Employers' contribution to health insurance programs

Pensions

Workers compensation

Life insurance premiums

Employee conference/training fees

FICA, unemployment insurance

contributions by employer

Outside services

Payments to consultants for survey development, data analysis, follow-up

studies, etc.

Data processing

Leased data processing services

Equipment/software specifically related

to DSM program

Allocation of costs for company data

processing facilities and related

equipment and supplies

Office supplies and other expenses Office supplies and routine expenses Photocopy, postage, printing, stationary, subscriptions, and communications expenses

Meals, travel, and incidental expenses All items not included elsewhere
Advertising

Conservation advertisements on radio, TV, newspaper, magazines, etc. Consultant payments for development of media ads

Materials and services used in displays Lease cost of phone lines/equipment for conservation hotline

\section{Equipment (expense)}

Fixed assets purchased for conservation with no alternative future use, or items whose unit cost is less than $\$ 500$

\section{Equipment (depreciation)}

Depreciation cost associated with assets purchased for the DSM program whose unit cost exceeds $\$ 500$ for which an alternative future use exists

Gain or loss on sale of assets

\section{Rebates}

Cost of cash rebates paid to customers or dealers for purchasing or selling conservation devices.

Conservation devices purchased by utility and distributed to customers

Administration

Costs that cannot be charged directly to one of the other cost elements (e.g., staff which supervise more than one project and common office/telephone equipment)

Source: New York DPS (1990b). 
Table 15. Categories of costs incurred by utilities, trade allies, and customers

\begin{tabular}{lccc}
\hline Category of cost & Utility & Trade ally & Customer \\
\hline Administrative & $\mathrm{X}$ & $\mathrm{X}$ & $\mathrm{X}$ \\
Marketing & $\mathrm{X}$ & $\mathrm{X}$ & \\
Monitoring/evaluation & $\mathrm{X}$ & $\mathrm{X}$ & \\
Equipment & $\mathrm{X}$ & $\mathrm{X}$ & $\mathrm{X}$ \\
Incentives & $\mathrm{X}$ & $\mathrm{X}$ & \\
\hline
\end{tabular}

To avoid confusion, incremental equipment costs net of rebates paid by the utility should be reported for the customer. For example, a customer elects to purchase a highefficiency room air conditioner for $\$ 500$ that is eligible for a $\$ 50$ rebate from the utility. Without the rebate, the customer would have purchased a less efficient model for $\$ 425$. The incremental equipment cost is $\$ 75$ ( $\$ 500$ less $\$ 425), \$ 25$ is reported as the customer's net cost, and the $\$ 50$ incentive is reported as a utility cost.

Each of these cost categories is discussed below.

\section{ADMINISTRATIVE COSTS}

Administrative costs are incurred by the utility for staff involved in program planning, design, marketing, implementation, and evaluation. They include labor-related expenses, office supplies, data processing, and other such costs. They exclude the costs of marketing materials and advertising, purchases of equipment for specific programs, and rebates or other cash incentives.

The magnitude of administrative costs will vary with a program's maturity. Some new programs will have high start-up costs. Start-up costs are those higher costs incurred initially to get a program implemented. For example, more intensive trade-ally and staff training is usually required in the first year of a program's implementation. As an example, New York State Electric \& Gas Corporation's (1990) reported costs for its load-control program for the first year of operation were twice the projections for the following years.

Program planning and development costs are sometimes included in administrative costs of the program if they can be attributed directly to a particular program. Some planning costs are not easily allocated to a specific program and may be tracked as a separate project. Such costs can include establishing a data-collection system and database management system to collect and analyze a program's cost and impact information. In some cases, program planning and development include the design, implementation, and analysis of a pilot program. 
The costs of contractors used for program administration should also be captured as administrative costs. Costs of contractors involved in the planning, implementation, and evaluation of a program are frequently combined in one cost category. Both Central Maine Power and New York State Electric \& Gas report all contractor costs in one category.

Customers may also incur administrative costs arranging for the installation of the equipment or measure. These customer administrative costs may be difficult to estimate and are not usually reported unless they are significant.

\section{MARKETING COSTS}

Marketing costs include all costs directly associated with the preparation and implementation of the marketing strategies. Marketing can be a significant portion of program costs, particularly when rebates are not offered, so it is important to report marketing in a separate category. Marketing costs may be incurred for direct mailings (letters and brochures), bill stuffers, telemarketing, trade shows and exhibitions, media advertising, point-of-purchase displays, videotapes, direct contact, and meetings or training sessions. The level and type of marketing are major factors in the success of a DSM program.

Marketing costs are not always reported in a consistent manner. NORDAX (1990) collects data for eleven categories under variable marketing costs. The utilities in New York report costs for promotion as a separate category. Central Maine Power includes "advertising/telemarketing" as a category in its monthly reports. A number of other utilities simply combine marketing costs with program administration costs.

\section{MONITORING AND EVALUATION COSTS}

Program monitoring and evaluation costs may or may not be included in total program costs. These costs are incurred for data collection and analysis to assess the performance of the DSM program. Although monitoring and evaluation costs are reported by the California utilities, the Standard Practice Manual specifically excludes from its costeffectiveness tests, the "costs associated with the measurement and evaluation of program impacts unless the costs are a necessary component to administer the program" (California Collaborative 1990). In Massachusetts, on the other hand, these costs are included in analysis of program costs and benefits. NORDAX includes evaluation costs in the "administrative fixed" category.

Although a number of utilities, including those in New York, report programevaluation costs in their annual DSM filings, not all related monitoring and evaluation costs are always included. It is not uncommon for customer surveys used in program evaluation to be conducted by a market research group not directly connected with the DSM function. Customer appliance saturation surveys provide necessary data for estimating eligible markets, free ridership, and other DSM market characteristics. Since these surveys have been 
conducted routinely for many years and have been included in a market research budget, the expenses are not always captured in DSM program-evaluation costs.

Technology assessments are another important component of program evaluation that is not always charged to DSM program costs. Technology assessments are studies of the performance of new equipment, appliances, or measures. Development and support projects facilitate DSM programs. A development project is a forerunner of a particular DSM program. A support project develops a tool, such as a database, that will facilitate a number of DSM programs. Development and support projects include the collection of data to refine base-case end-use estimates, the development of DSM tracking systems to monitor program performance, and the implementation of modeling systems to predict market penetration.

\section{EQUIPMENT COSTS}

Equipment costs are costs of equipment purchased directly by the utility. (If the utility helps pay for equipment purch'ssed by another party, these costs are considered incentives and are discussed in the next subsection. Clearly, costs should not be counted twice.) Equipment costs include equipment that affects customer electricity use directly as well as equipment necessary for the operation or monitoring of the program.

Several categories of equipment used in DSM programs directly affect electricity use (Table 16). One category includes the end-use or energy-using equipment being promoted by the program. This category can include faucet-flow restrictors that are very inexpensive or cool storage systems that require a major capital investment. The costs of materials or new energy-efficient equipment are also included in the equipment category. Building-shell insulation and clock thermostats for space-heating systems are examples. Control technologies constitute another category of equipment that affects the use of electricity. Control technologies are used to regulate equipment and include energy management systems and controllers for load control or cycling. NORDAX (1990) combines equipment, materials, and control technologies into a single category called end-use technology, defined as "major categories of appliances, equipment, materials or processes which convert or affect the conversion of electricity and other sources of energy into services such as heating, cooling, illumination, or motive power."

Other types of equipment purchased for DSM programs do not directly affect electricity use but are needed for program operation or monitoring. For example, metering equipment, used to collect data on electricity consumption, including load data for program monitoring, may or may not be included in the same equipment-cost category as end-use technologies. Another category of equipment that does no: directly affect electricity use is equipment required to communicate information that will help customers achieve desirable load effects. For example, personal computers are sometimes used to relay pricing information to customers for real-time pricing programs. 
Table 16. Examples of equipment costs

\author{
Equipment or materials \\ End-use equipment \\ Material \\ Control technologies \\ Special metering \\ Personal computers \\ Installation \\ Shipping \\ Loan applications \\ Finance/interest charges
}

Operation and Maintenance

Fuel

Equipment servicing

Equipment storage

Removal and disposal (less salvage value)

A number of equipment-related costs are not always captured in the equipment category. These include disposal costs. Incremental removal and disposal costs can be incurred for disposal of working refrigerators or mercury-vapor lamps. The salvage value of equipment purchased for a program and lasting beyond the program's life should be considered when quantifying equipment-related costs. Equipment targeted for early replacement or early retirement will often have a salvage value. For example, a number of utilities are converting municipal street-lighting systems from mercury-vapor to high-pressure sodium lamps. The replaced but working mercury-vapor lamps are: (1) disposed of in an environmentally safe manner, (2) put back in stock to replace defective mercury vapor lamps in areas not yet scheduled for conversion, or (3) sold to other companies outside the service area.

Substantial costs can be incurred for removal of equipment at the conclusion of a DSM program. For example, Long Island Lighting Company is discontinuing a residential load-control program because it is not cost effective. The cost of removing load-control devices from customers' homes is large enough to be tracked as a program cost.

Several options are available for handling the purchase and installation of equipment or measures. Alternative approaches used by utilities include:

The customer purchases and installs the equipment (with or without the use of a contractor).

- The utility purchases and installs the equipment using its own staff.

The utility contracts with an energy service company or other contractor to acquire, stock, and install the measures.

The utility purchases the equipment and contracts with an energy-service company or other contractor to have the equipment installed. 
The accounting for equipment purchased for DSM programs varies with a number of factors, including ownership, cost, and expected salvage value. Equipment is often capitalized and depreciated if the equipment is owned by the utility. Equipment that is capitalized is considered an investment to be used over a multiyear period and therefore eligible for ratebasing. The New York DPS (1990)b) specifies that utilities should capitalize equipment if it exceeds a cost of $\$ 500$ or is expected to have value beyond the life of the program. Capitalized equipment is ratebased, and the utility is able to earn a rate of return on the equipment cost. Special meters for time-of-use rate programs are an example. Equipment purchased by a utility in New York will be expensed if the cost is low and no salvage value is expected. Expensed equipment generally has a short useful life, is not included in rate base, and the utility cannot earn a rate of return on the expenditure. Compact fluorescent lights are an example.

The equipment costs can be incurred by contractors. For example, Eastern Utilities Associates (1990) runs programs that include the direct installation of water-heater blankets, low-flow shower heads, compact fluorescents, and other measures. They selected a contractor to acquire, stock, and install these low-cost measures. If these are the only equipment costs incurred for the program, it may be appropriate to report them in one equipment category. But the contractor's administrative costs should be tracked separately.

Customers often incur the equipment costs associated with participation in a DSM program. Costs are usually reported as incremental costs, the difference in costs for the efficient technology being promoted by the program and the standard technology that would have been installed in the absence of the program. For some early retirements and retrofits, the full cost of the efficient technology is the incremental cost. For example, the full cost of replacing a working, reasonably new, electric water heater with a new high-efficiency model is the appropriate incremental cost. The incremental cost of adding more insulation to an existing building is the entire cost of the materials and the installation. For new construction, the utility must decide what would have been installed in the absence of the program and use that standard equipment or building-shell specification to calculate incremental cost. Many of the errors associated with reporting equipment costs could be eliminated if utilities tracked and reported the average unit cost of baseline measures (those installed without the DSM program) and high-efficiency measures (those promoted by the program).

Although the installed costs of the equipment are usually one-time costs, incremental operating and maintenance costs are not. They are the noncapital, equipment-related costs that continue during the life of the equipment. Operating and maintenance costs include fuel costs as weli as costs for maintaining and servicing equipment.

Avoided equipment costs should be included when calculating the incremental cost of the equipment. For example, a compact fluorescent light bulb with a rated life of 10,000 hours replaces 13.3 incandescent bulbs with a rated life of 750 hours. The cost of the 13.3 incandescents should be deducted from the price of the compact fluorescent to arrive at the incremental cost of the fluorescent. 


\section{INCENTIVE COSTS}

Utilities often provide incentives (awards intended to motivate participation in DSM programs and to encourage adoption of recommended measures) to customers, trade allies, and employees. Incentives can include cash incentives, such as rebates and cash payments, and noncash incentives, such as low-interest loans, reduced equipment costs, bill credits or discounts, merchandise, and free services (Table 17). Most utilities offering incentives have record-keeping systems to provide detailed information.

Rebates are provided to customers, contractors, homebuilders, and other trade allies who make equipment-choice decisions to help defray the incremental cost of the DSM measure. Rebate costs can be a significant portion of total program costs. For example, Central Maine Power Company's customer rebates for its commercial lighting program totalled $85 \%$ of program costs in 1989.

Low-interest loans are another form of incentive sometimes offered to help defray the high up-front costs of major building-shell improvements or equipment changeouts. The incentive to the customer includes the difference in cost between the low interest rate paid by the participating customer and the interest rate financial institutions normally charge.

Utilities sometimes provide equipment directly at lower cost rather than offer rebates for equipment purchased by customers. Many residential programs provide low-cost equipment or conservation devices at substantially reduced cost or no cost. For example, Central Maine Power Company purchased about 90,000 compact fluorescent light bulbs for about $\$ 18$ each and sold them to the Lions Club at $\$ 1$ each. The Lions Club then distributed them to residential customers in Central Maine Power Company's service area by selling them for $\$ 3$ each. The customer received an incentive of at least $\$ 15$, which is the difference between the retail price of the compact fluorescent and the cost to the participants (roughly $\$ 18$ minus $\$ 3$ ). In essence, the utility bought the lamps for $\$ 18$ each, gave its customers a $\$ 15$ rebate, and paid the Lion's Club $\$ 2$ for each bulb the club sold. However, the utility netted the $\$ 1$ from the Lions Club against its purchase price and included this $\$ 1$ in the equipment category for utility-program costs, and reported no incentive costs. If Central Maine Power Company had offered a rebate, the $\$ 3$ would have been included in customer equipment costs, and the $\$ 15$ rebate would have been categorized as a utility cost. These differences in reporting make it difficult to compare programs that offer the same DSM technology to the same eligible market but with differing marketing and delivery approaches.

Trade allies' willingness to stock and promote the more efficient technology greatly influences the success of a program. Recognizing the importance of the trade allies' role, utilities often provide cash incentives or merchandise to trade allies for purchasing and/or installing equipment being promoted by the DSM program. 
Table 17. Examples of types of incentives by incentive recipient

\begin{tabular}{ll}
\hline Targeted group & Type of incentive \\
\hline Customers & Services (provided free or at a reduced cost) \\
Technical assistance \\
Engineering design \\
Energy audits \\
Equipment installation \\
Cash rebates for equipment \\
Bill credits (specific monthly or annual bill credits) \\
Rate discounts \\
Loans (zero- or low-interest rates) \\
Equipment leasing \\
Performance-based incentives \\
Payments for $\mathrm{kW}$ reductions \\
Payments for kWh savings \\
Payback buydown \\
Cash rebates for equipment \\
Gifts or merchandise \\
Cash awards \\
Subsidized warehousing \\
Performance-based incentives \\
Payments for kW reductions \\
Payments for kWh savings \\
Cash awards \\
Gifts or merchandise \\
\end{tabular}

Utilities often offer free or subsidized feasibility studies for nonresidential-sector programs involving major investments in new building construction or equipment. Feasibility studies are provided by consultants or utility staff trained to assess the costs, benefits, and technological considerations for a customer considering the installation of specific measures. BPA, Boston Edison, and Northeast Utilities are among the utilities that offer technical assistance during the design phase of new buildings and their HVAC systems. Utilities may cover all or part of the costs for an engineering consulting firm to assess the costs and benefits of a cool-storage system. Other free services offered by utilities include energy audits and equipment maintenance, such as refrigerator or air conditioner tune-up programs. Also, some utilities offer a bill credit to customers who participate in water-heater- or airconditioner-cycling programs. This may be a monthly or annual credit to a utility bill. Rate discounts, lower rates for specified time periods, are also included in program costs as incentives. 
Utilities use performance-based incentives to match benefits or avoided costs to the actual peak demand and/or energy savings. These incentive payments are usually calculated on the basis of $\mathrm{c} / \mathrm{kWh}$ or $\$ / \mathrm{kW}$. In some cases, incentives are based on measured savings. In other cases, payment is made up front, based on expected savings projected by engineering studies.

Utilities do not consistently report all these types of incentives in one category. NORDAX has an unusual requirement to report all types of incentives, both cash and noncash, under marketing costs. These costs are divided between fixed costs, which do not vary by number of participants, and variable costs, which vary with the number of participating units. Administrative costs associated with the processing of the incentives are included in the fixed and variable marketing costs. Detailed information on the dollar value of incentives paid to customers, utility employees, and trade allies is collected in a separate table.

\section{DEMAND-SIDE BIDDING PROGRAM COSTS}

Demand-side bidding programs are based on a competitive bidding process. The utility issues a request for proposals for demand-side resources. Potential bidders include energy-service companies, customers, and other utilities. Demand-side bid programs may result in the bulk of the costs being paid to an energy-service company. Different energyservice companies often bid total program costs that include cost categories at different levels of detail. For these types of programs, the utility should specify a cost-reporting structure that is as rigorous as requirements for utility-sponsored programs.

\section{REGULATORY INCENTIVES}

In many states, agreements with regulators allow utilities to earn bonuses or incentives for good performance in demand-side management. These agreements vary from state to state and even among utilities in a given state. To the extent that these regulatory incentives add to the cost of the program to ratepayers, they should be reported. These costs are explicitly included as program costs in Massachusetts and California.

\section{TIMING ISSUES}

The reported time frame of program costs does not always match the dates of actual expenditure. In some cases, utilities may accrue all the budgeted dollars for a large incentive program in a balancing account beginning in the year this is first allowed. A balancing account is a special account for reconciling expenditures with revenues to ensure that the utility collects thr ugh rates no more and no less than is authorized. Utilities also may report payments to customers at the time of obligation. Still others report the expenditure only when payment is actually made to the customer. Regulatory cost recovery and incentive 
agreements or special cost-reporting practices may influence the reporting of program costs. If the costs are expensed, the utility is more likely to report expenditures on an annual basis. If the costs are capitalized, the utility may report either full cost when accrued or only annualized capital costs (i.e., return of and on its investment).

In annual DSM reports, program costs are usually reported by calendar year. Cost information is not always available from the internal accounting system when it is needed. Costs attributed to the current year are frequently based on a combination of actual and projected costs. Regulators in New York, Maine, and Massachusetts require more frequent reporting, such as quarterly, bimonthly, or monthly. Utilities in California report program cost data on a semiannual basis. The more frequent the reporting basis, the more likely that all current costs will not be included.

Significant lags can occur for some types of costs that must go through internal invoice approval and processing. For example, a month may be required to approve and process advertising-agency bills. In addition, advertising agencies often do not submit their bills for several months. On the other hand, utilities can incur substantial costs in the year before a program begins for program planning and development of marketing materials and advertising. 


\section{PUTTING THE DATA TO USE}

The preceding chapters discussed the basic concepts that characterize utility DSM programs and offered definitions of the key data elements for these programs. These data cover participation, energy and load impacts, and costs. Appendix A presents a sample reporting form that utilities can use to report data on their DSM programs. And Appendix $\mathrm{B}$ defines all the terms shown on the Appendix A form. This chapter briefly describes how these data can be used by utilities, regulatory commissions, energy analysts, policy makers, and others.

\section{COST-BENEFIT CALCULATIONS}

As discussed by the California Public Utilities Commission and California Energy Commission (1987), these data can be used to assess the economic benefits and costs of DSM programs. This California Standard Practice Manual considers four perspectives from which the costs and benefits of such programs are considered: program participants, ratepayers (both participants and nonparticipants), utility, and total resource (Table 18). Other states use similar methods to determine program cost effectiveness.

Calculating the net present value of benefits and costs (or benefit/cost ratios) requires data and estimates beyond those discussed here. In particular, (1) estimates of marginal energy and capacity costs and (2) utility and consumer discount rates are important nonDSM factors used in these computations. The benefits of DSM programs, for all the perspectives shown in Table 18, depend on the estimates of electricity savings and load reductions (Chapter 4). The program costs, which are important for all perspectives except that of the participant, are discussed in Chapter 5.

\section{PROGRAM-PERFORMANCE INDICES}

Beyond the economic tests discussed above, the data discussed in this handbook can be applied to other purposes. Nadel (1991) discusses several simple indices that can be used to assess and compare the performance of utility DSM programs. These indices include: annual and cumulative participation rates, percentage reducticins in annual electricity sales and peak demands, fractions of participants that are free riders, the ratio of indirect-to-direct program costs, program cost-effectiveness indices $(c / \mathrm{kWh}$ and $\$ / \mathrm{kW})$, and the ratio of actual electricity savings to estimated savings. 
Table 18. Elements of the economic tests developed by the California Public Utilities Commission and California Energy Commission

\begin{tabular}{|c|c|c|}
\hline Perspective & Benefits & Costs \\
\hline Participant & $\begin{array}{l}\text { Reduced utility bills based } \\
\text { on gross savings plus } \\
\text { incentive from utility for } \\
\text { DSM measures }\end{array}$ & $\begin{array}{l}\text { Out-of-pocket costs } \\
\text { (exclusive of any utility } \\
\text { incentive) }\end{array}$ \\
\hline $\begin{array}{l}\text { Rate impact measure (all } \\
\text { ratepayers) }\end{array}$ & $\begin{array}{l}\text { Avoided supply costs } \\
\text { (production, transmission, } \\
\text { and distribution) based on } \\
\text { net savings }\end{array}$ & $\begin{array}{l}\text { Utility program costs, } \\
\text { including incentives to } \\
\text { participants, plus net lost } \\
\text { revenues }\end{array}$ \\
\hline $\begin{array}{l}\text { Utility (revenue } \\
\text { requirements) }\end{array}$ & $\begin{array}{l}\text { Avoided supply costs } \\
\text { (same as above) }\end{array}$ & $\begin{array}{l}\text { Utility program costs } \\
\text { (same as above) }\end{array}$ \\
\hline Total resource & $\begin{array}{l}\text { Avoided supply costs } \\
\text { (same as above) }\end{array}$ & $\begin{array}{l}\text { Total program costs to the } \\
\text { utility and participants } \\
\text { (i.e., measure costs plus all } \\
\text { administrative costs) }\end{array}$ \\
\hline
\end{tabular}

For example, a utility could compare participation rates for its commercial lighting program (based on the data discussed in Chapter 3 ) with the results obtained for similar programs conducted by other utilities. Such comparisons could consider differences in the programs in the amount of time they have been in existence, the market segments at which they are aimed, as well as the utility incentive and marketing budgets. Computation of the levelized cost of conserved energy $(\boldsymbol{c} / \mathrm{kWh})$ and the cost of capacity reductions $(\$ / \mathrm{kW})$ require data on energy savings and load reductions plus cost data.

\section{FUTURE EFFORTS}

As noted above, this handbook is neither the first nor the last effort to develop useful reporting formats and definitions to characterize utility DSM programs. Although we would like to believe that our prose is so clear and our reporting formats so compelling that no further effort is needed to ensure widespread adoption of our suggestions, we know this is not the case.

We recommend two types of "outreach" beginning in 1992. First, we suggest that DOE, the Electric Power Research Institute, and the National Association of Regulatory Utility Commissioners sponsor workshops in several locations throughout the U.S. These 
workshops would provide instructions to utility and PUC staff on how to complete these forms and how to use the results so obtained. Second, we suggest several case studies, in which utilities would use these forms for data collection, reporting, and analysis. Such field use of these definitions and the reporting form would yield valuable guidance on how to improve this handbook. Indeed, the "pretest" of the Appendix A form by program managers at six utilities for nine programs provided important ways to improve the current form. 


\section{ACKNOWLEDGMENTS}

The Office of Conservation and Renewable Energy of the U.S. Department of Energy (Diane Pirkey) and the Customer Systems Division of the Electric Power Research Institute (Philip Hanser) provided funds to prepare this handbook. In addition, the Energy Conservation Committee of the National Association of Regulatory Utility Commissioners (Sam Swanson) played a key role in supporting this work. A Committee on DSM-Program Terminology oversaw the definition, development, and review of this handbook. The committee members, who spent considerable time reviewing drafts of these chapters and participating in committee meetings, include:

Kenneth Black, Philadelphia Electric Company

Michael Cheng, Pacific Gas \& Electric Company

Martin Cummings, New York Department of Public Service

Philip Hanser, Electric Power Research Institute

Jeffrey Harris, Lawrence Berkeley Laboratory

Elizabeth Hicks, New England Power Service Company

Craig Kazin, New England Power Planning

Kenneth Keating, Bonneville Power Administration

Nancy Korda, Wisconsin Public Service Commission

Dale Landgren, Wisconsin Electric Power Company

Diane Pirkey, U.S. Department of Energy

Lawrence Prete, U.S. Department of Energy

Jonathan Raab, consultant

Don Schultz, California Public Utilities Commission

Sam Swanson, New York Public Service Commission

Richard Tempchin, Edison Electric Institute.

In addition, Linda Berry, Ken Camera, Frank Congedo, William Eastlake, John Hughes, Bill LeBlanc, Cynthia Melendy, Steven Nadel, Dan Quigley, Deborah Ross, Edward Vine, Stephen Wiel, and Amy Wolfe reviewed drafts of this handbook. Joseph Barrington; William Blake; Sharon Doggett; May Hing; A. J. McDevitt, Jr; John Peloza; and Michael Voltz pretested the Appendix A reporting form and offered valuable suggestions for improving it. Finally, Fred O'Hara edited the final handbook and Ethel Schorn proofread and assembled the final report. 


\section{REFERENCES}

D. P. Bergeron and R. B. Parker 1989, "How the Maine PUC Uses Standardized Utility Reports to Monitor Program Cost Effectiveness," Demand-Side Management: Partnerships in Planning for the Next Decade, Proceedings of the ECNE National Conference on Utility DSM Programs, EPRI CU-6598, Electric Power Research Institute, Palo Alto, CA, November.

L. Berry 1989, The Administrative Costs of Energy Conservation Programs, ORNL/CON-294, Oak Ridge National Laboratory, Oak Ridge, TN, November.

L. Berry 1990, The Market Penetration of Energy-Efficiency Programs, ORNL/CON-299, Oak Ridge National Laboratory, Oak Ridge, TN, April.

J. Blagden 1991, personal communication, Barakat \& Chamberlin, Oakland CA, May.

Boston Edison Company 1989, Status Report, Encore, Energy Conservation Retrofit Program, Boston, MA, March.

M. A. Brown, D. L. White, and S. L. Purucker 1987, Impact of the Hood River Conservation Project on Electricity Use for Residential Water Heating, ORNL/CON-238, Oak Ridge National Laboratory, Oak Ridge, TN, October.

California Collaborative 1990, "Appendix A: Measurement Protocols for DSM Programs Eligible for Shareholder Incentives," An Energy Efficiency Blueprint for California, January.

California Energy Commission 1990, 1990 Electricity Report, P106-90-002, Sacramento, CA, October.

California Public Utilities Commission and California Energy Commission 1987, Economic Analysis of Demand-Side Management Programs, San Francisco and Sacramento, CA, December.

California Public Utilities Commission 1990, Demand-Side Management Reporting Requirements Manual, 4th ed., San Francisco, CA, December.

California Public Utilities Commission 1991, Order Instituting Rulemaking on the Commission's Own Motion to Establish Rules and Procedures Governing Demand-Side Management, I.91-08-002, San Francisco, CA, August. 
D. W. Caves, M. N. Lowry, and J. B. Wharton 1989, "Evaluating Alternative Measures of Credited Load Relief: Results from a Recent Study for New England Electric," DemandSide Management: Partnerships in Planning for the Next Decade, Proceedings of the ECNE National Conference on Utility DSM Programs, EPRI CU-6598, Electric Power Research Institute, Palo Alto, CA, November.

J. H. Chamberlin and P. E. Hanser 1991, "Current Designs of Regulatory Techniques to Encourage DSM," Proceedings National Conference on Integrated Resource Planning, pp. 316326, National Association of Regulatory Utility Commissioners, Washington, DC, April.

R. E. Ciliano and B. K. Hinkle 1991, An Evaluation of the NORDAX Database and Services and the Needs of Member Utilities, RCG/Hagler, Bailly, Inc., Philadelphia, PA, June.

T. M. Dinan and D. Trumble 1989, "Temperature Takeback in the Hood River Conservation Project," Energy and Buildings 13(1), 39-50.

Eastern Utilities Associates 1990, Conservation and Load Management Activities, Annual Report 1989, West Bridgewater, MA, April.

Edison Electric Institute 1991, Glossary of Electric Utility Terms, Washington, DC.

Energy Information Administration 1989, "Commercial Buildings Energy Consumption Survey for 1989 Building Questionnaire," Form EIA-871A, U.S. Department of Energy, Washington, DC.

Energy Information Administration 1990, PC-AEO Forecasting Model for the Annual Energy Outlook 1990, Model Documentation, DOE/EIA-M036(90), U.S. Department of Energy, Washington, DC, March.

Energy Information Administration 1991, "Schedule V, Demand-Side Management Information (Actual and 10-Year Forecast)," Form EIA-861, U.S. Department of Energy, Washington, DC, January.

Executive Office of the President 1987, Standard Industrial Classification Manual, National Technical Information Service, Springfield, VA.

M. F. Fels, editor 1986, "Special Issue Devoted to Measuring Energy Savings: The Scorekeeping Approach," Energy and Buildings 9 (1 and 2), February/May.

G. Fitzpatrick 1991, personal communication, Applied Energy Group, Woodbury, NY, March.

D. L. Greene 1991, Vehicle Fuel Use and Fuel Economy: How Big is the "Rebound" Effect?, Oak Ridge National Laboratory, Oak Ridge, TN, February. 
J. Henly, H. Ruderman, and M. D. Levine 1988, "Energy Savings Resulting from the Adoption of More Efficient Appliances," The Energy Journal 9(2), 163-170, April.

E. Hirst 1990, Balancing the Scales: Data on Electricity Supply and Demand, ORNL/CON306, Oak Ridge National Laboratory, Oak Ridge, TN, September.

E. Hirst 1991, "Fulfilling the Demand-Side Promise," Public Utilities Fortnightly 128(1), 31-32, July 1 .

E. Hirst, D. White, E. Holub, and R. Goeltz 1985, Actual Electricity Savings for Homes Retrofit by the BPA Residential Weatherization Program, ORNL/CON-185, Oak Ridge National Laboratory, Oak Ridge, TN, July.

J. D. Khazzoom 1987, "Energy Savings Resulting from the Adoption of More Efficient Appliances," The Energy Joumal 8(1), 85-89, October.

F. Krause, E. Vine, and S. Gandhi 1989, Program Experience and its Regulatory Implications: A Case Study of Utility Lighting Efficiency Programs, LBL-28268, Lawrence Berkeley Laboratory, Berkeley, CA, October.

Massachusetts Department of Public Utilities 1989, Filing Format for Annual C\&LM Reports, Boston, MA, August.

S. Nadel 1990a, "Electric Utility Conservation Programs: A Review of the Lessons Taught by a Decade of Program Experience," pp. 8-179-8.206, Utility Programs, Vol. 8 of Proceedings, ACEEE 1990 Summer Study on Energy Efficiency in Buildings, American Council for an Energy-Efficient Economy, Washington, DC, August.

S. M. Nadel 1990b, The Achievable Conservation Potential in New York State from Utility Demand-Side Management Programs, American Council for an Energy-Efficient Economy, Washington, DC, November.

S. Nadel 1991, "Use of Simple Performance Indices to Help Guide Review of DSM Program Performance," Proceedings National Conference on Integrated Resource Planning, pp. 116-130, National Association of Regulatory Utility Commissioners, Washington, DC, April.

S. M. Nadel and K. M. Keating 1991, "Engineering Estimates vs Impact Evaluation Results: How Do They Compare and Why," pp. 24-33, Energy Program Evaluation: Uses, Methods and Results, Proceedings of the 1991 International Energy Program Evaluation Conference, CONF-910807, August.

New England Power Planning 1990a, NEPOOL Participant Planned Demand-Side Management Impacts on the NEPOOL Load Forecast, 1990-2005, Holyoke, MA., April. 
New York Department of Public Service 1990a, Formats and Guidelines for July 23, 1990 DSM Plan Filing in Case 28223, Albany, NY, March.

New York Department of Public Service 1990b, Report of the New York Public Service Commission Concerning a Common Accounting Method for Allocating Costs of Specific DSM Programs, Case 28223, Albany, NY, May.

New York Department of Public Service 1990c, "Proceeding to Inquire into the Benefits to Ratepayers and Utilities from Implementation of Conservation Programs that will Reduce Electric Use," Order Concerning 1991 and 1992 Demand-Side Management Plans, Case 28223, New York, NY, November.

New York State Electric \& Gas Corporation, 1990 Demand-Side Management Filing, Vol. II: 1991-1992 Annual DSM and HIECA Plan, Binghamton, NY, October.

Northeast Region Demand-Side Management Data Exchange 1989a, The Development of the Data Collection Instrument and the Data Collection Process, Edison Electric Institute, Washington, DC, June. See also Demand-Side Management Utility and Program Data Collection Survey, April 1989, and October 1990 revision of the Data Collection Instrument.

Northeast Region Demand-Side Management Data Exchange 1989b, ivoRDAX: A Regional Demand-Side Management Database, Final Report, No. 07-89-32, Edison Electric Institute, Washington, DC, March.

Northeast Region Demand-Side Management Data Exchange 1990, NORDAX: A Regional Demand-Side Management Database, SRC Report 7462-R1, Synergic Resources Corporation, Bala Cynwyd, PA, October.

Ontario Hydro 1991, Incentives and the Success of DSM Programs, An Examination of Other Utility Experiences, Screening \& Evaluation Unit, Ontario Hydro, Toronto, Canada, January.

Pacific Gas and Electric Company 1991, Annual Summary Report on Demand Side Management Programs in 1990 and 1991, San Francisco, CA, March.

M. Parti and C. Parti 1980, "The Total and Appliance Specific Conditional Demand for Electricity in the Household Sector," Bell Journal of Economics 11(1), 309-321, Spring.

G. M. Rueger 1991, testimony before the U.S. Senate Committee on Energy and Natural Resources, Pacific Gas \& Electric Company, San Francisco, CA, February 26.

C. Sabo, and I. Birnbaum 1990, Summary of DSM Program Experience, The North Carolina Alternative Energy Corporation, Barakat \& Chamberlin, Washington, D.C., November. 
C. Sabo, M. McRae, and C. Donner 1990, Long Island Lighting Company Operational and Market Review of 1989 Energy Consenation and Load Management Programs, Barakat \& Chamberlin, Washington, D.C., February.

W. P. Saxonis 1989, "Program Evaluation of the New York State Energy Efficient Appliance Rebate Demonstration Program: The Free Rider Factor," Energy Program Evaluation: Conservation and Resource Management, Proceedings of the August 23-25, 1989, Conference, pp. 237-240, Argonne National Laboratory, Argonne, IL, August.

S. Schick, I. Birnbaum, J. Blagden, and M. Adelaar 1990, Review and Assessment of North American Utility Experience with Residential Energy Efficiency Programs, Barakat \& Chamberlin, Inc. and Marbek Resource Consultants, Ltd., prepared for Ontario Hydro, Toronto, June.

M. Schweitzer, M. A. Brown, and D. L. White 1989, Electricity Savings One and Two Years after Weatherization: A Study of 1980 Participants in Bonneville's Residential Weatherization Program, ORNL/CON-289, Oak Ridge National Laboratory, Oak Ridge, TN, September.

D. H. Sumi and B. Coates 1989, "Persistence of Energy Savings in Seattle City Light's Residential Weatherization Program," Energy Program Evaluation: Conservation and Resource Management, pp. 311-316, Argonne National Laboratory, Argonne, IL, August.

K. E. Train and P. C. Ignelzi 1987, "The Economic Value of Energy-Saving Investments by Commercial and Industrial Firms," Energy 12(7), 543-553, July.

U.S. Congress 1990, An Act 10 Amend the Clean Air Act, Public Law 101-549, Washington, DC, November 15.

D. Violette, M. Ozog, M. Keneipp, F. Stern, and P. Hanser 1991, Impact Evaluation of Demand-Side Management Programs, Volume 1: A Guide to Current Practice, EPRI CU-7179, Electric Power Research Institute, Palo Alto, CA, February.

D. L. White, B. E. Tonn, and T. K. Stovall 1991, Persistence of the Impact of the Hood River Conservation Project on Typical and Peak Loads: Three Years after Weatherization, ORNL/CON-321, Oak Ridge National Laboratory, Oak Ridge, TN, March.

Wisconsin Public Service Commission 1990, Least-Cost Planning Guidelines for Wisconsin, Madison, WI, March. See also Wisconsin Public Service Commission 1990, "Statewide Dataform Item Definitions," Madison, WI, November.

Xenergy Inc. 1990, Demand Side Management Program Evaluation Scoping Study, ESEERCO Project EP90-34, prepared for Empire State Electric Energy Research Corp., New York, NY, November. 


\section{APPENDIX A. DSM-PROGRAM DATA REPORTING FORM}

NAME AND LOCATION OF UTILITY

PROGRAM NAME

(city, state)

PERIOD FOR WHICH DATA APPLY

(12-month period preferred)

PROGRAM MANAGER

$$
\text { name }
$$

phone number

PERSON COMPLETING

FORM

$$
\text { name }
$$

phone number

date

PROGRAM DESCRIPTION

DSM TECHNOLOGIES, PRACTICES, AND END USES PROMOTED

PROGRAM OBJECTIVE(s) - Mark $\mathbf{P}$ for primary objective and $\mathbf{S}$ for all secondary objectives

$\begin{array}{lll}\text { Energy efficiency } & \text { - Load shifting } \\ \text { - Peak clipping } & \text { Valley filling }\end{array}$

PROGRAM TYPE(s) - P = primary, $S$ = secondary

- General information

Incentives
- to customers
- to trade allies
- to utility employees

Fuel switching

(from to
Load control

- Alternative rates

_ Time-of-use

- Interruptible/curtailable

- Other (explain:

PROGRAM DELIVERY AGENT(s) - P = primary, $S$ = secondary

_Utility _ Energy service company _ Other contractor

_ Government agency

PROGRAM LIFE-CYCLE STAGE (note start date for current and earlier stages)

Start date (month/ycar)

End date (month/year)

Filot program

_ Full-scale program 


\section{PROGRAM PARTICIPATION}

Eligibility criteria (used to define eligible market and participation)

ELIGIBLE MARKET(s):

$(\mathrm{P}=$ primary, $\mathrm{S}=$ supplemental $)$

New construction (including renovations to existing stock)

Existing:

Retrofit

Normal replacement

Early replacement

Early retirement
CUSTOMER CLASS(es):

$(\mathrm{P}=$ primary, $\mathrm{S}=$ supplemental)

Residential

Low-income

Commercial

Industrial

Agricultural

Other

(specify)

\section{EXISTING MARKET AND ANNUAL PARTICIPATION}
Annual
Cumulative

Size of eligible market*

Size of applicable customer class

Number of participants*

Participation rate $(\%$ of eligible market)

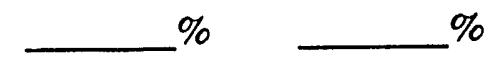

Participation rate (\% of applicable customer class)

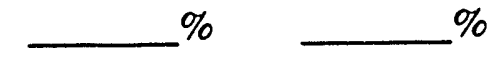

COMPLETE THIS PART ONLY FOR PROGRAMS FROM WHICH

PARTICIPANTS CAN DROP OUT

Annual participants (number):

Repeats

New

Dropouts

*Definition of participants and of eligible market if other than number of customers: 


\section{ENERGY AND LOAD EFFECTS}

(reported at the customer meter, exclusive of T\&D losses, $+=$ savings, $-=$ increase)

Gross effects

\begin{tabular}{|c|c|}
\hline Ene & (GWh/year) \\
\hline $\begin{array}{l}\text { nnual } \\
\text { his year) }\end{array}$ & $\begin{array}{l}\text { Cumulative } \\
\text { (since program inception) }\end{array}$ \\
\hline
\end{tabular}

Net effects

Lifetime of programmatic energy effects (years)

Diversified coincident peak demand effects (MW)

\begin{tabular}{lllll} 
& \multicolumn{2}{c}{ Summer peak } & \multicolumn{2}{c}{ Winter peak } \\
Gross effects & Annual $\quad$ Cumulative & Annual & \\
Net effects & & & \\
\hline
\end{tabular}

Basis of estimates $(\mathrm{P}=$ primary, $\mathrm{S}=$ supplemental)

Data Participants Nonparticipants

Estimates obtained from

other utility(ies)

Monthly electricity bills

Spot metering

Whole-building load data

End-use load data

What types of load-shape data are available on this program?

24-hour load shapes tor day types 8760-hour annual load shapes

Analytical methods Engineering calculations Comparisons of energy data Statistical analysis Hybrid (combination) methods 
ANNUAL PROGRAM COSTS (thousands of dollars)

(Report costs incurred for specified ycar only without double counting)

Utility Costs

Administrative

Labor-related

All other

Marketing

Monitoring and evaluation

Equipment

Cash incentives:

Customers

Trade allies

Employees

Noncash incentives:

Customers

Trade allies

Employees $\underline{\text { Nonutility costs }}$

Participant costs:

(net of incentive

from utility)

Other costs:

(not paid by utility)

(specify)

Total nonutility costs

Other costs (DSM bidding, incentives to sharcholders, etc.)

Total utility costs

Total program cost

Cost of utility incentive relative to:

Total program cost DSM-measure costs $\%$

DSM-measure costs relative to total cost $\%$ 


\section{APPENDIX B. GLOSSARY OF KEY DSM-PROGRAM TERMS ${ }^{1}$}

Achievable potential is an estimate of the amount of energy savings that would occur if all cost-effective, energy-efficient options promoted through utility DSM programs were adopted.

Add-ons are purchases of new or additional equipment of a type previously not present in an existing facility, such as the purchase of a food freezer for a home that previously had none or the purchase of a second room air-conditioner.

*Administrative costs are expenses incurred by the utility for program planning, design, management, and administration. They include labor, office supplies, data processing, and other such costs. They exclude the costs of marketing, purchase of equipment for programs, incentives, and monitoring and evaluation.

*Agricultural sector is the group of nonresidential custorners engaged in the production of crops or livestock, forestry, fishing, hunting, or trapping.

*Alternative-rate programs offer special rate structures or discounts on the customer's monthly electric bill, often in return for participation in programs aimed at cut ting peak demands or changing load shape.

* Annual effects are the changes in customer electricity use and demand caused by a program's activities during a given year.

* Annual participation is the number of customers enrolled in a particular program for a given year.

*Annual participation rate is the ratio of the number of participating units in a particular year to the number of eligible units.

Base market is the set of customers or technologies against which participation in a program is measured.

Bill credit is a payment in the form of a reduction in a customer's electricity bill.

Capitalized refers to equipment or other utility investments to be used over a multiyear period and therefore eligible for inclusion in the utility's ratebase.

* Cash incentive is a monetary award or inducement in the form of a rebate or payment.

${ }^{1}$ An asterisk $\left({ }^{*}\right)$ refers to terms that are in the Appendix A reporting form. 
* Coincident peak demand is the load (in $\mathrm{kW}$ ) of an end use, customer, or group of customers at the time the utility experiences its greatest demand for electricity.

*Commercial sector is the group of nonresidential customers that provides services, including retail, wholesale, finance, insurance, and public administration.

* Cumulative effects are the changes in electricity use and demand caused by all of a program's participants from the program's inception through the current year.

*Cumulative participation is the number of participating units from the start of a program through the current year.

*Cumul-tive participation rate is the ratio of the number of participating units from the start of a program through the current year to the number of eligible units.

* Customer class is a group of customers with similar characteristics, such as economic activity or level of electricity use.

Customer unit is a measure of participation that is based on customers, households, or buildings in contrast to technology units.

* Demand-side bidding programs are processes in which the utility issues a request for proposals to acquire demand-side resources, receives proposals from customers and energyservice companies, reviews the proposals, negotiates contracts with the winning bidders, and takes delivery of the energy savings and load reductions called for in the contracts.

Demand-side management measures are actions taken by a customer (e.g., installation of energy-efficient equipment) to modify the amount or timing of electricity use.

${ }^{*}$ Demand-side management programs are organized utility activities that are intended to affect the amount and timing of customer electricity use.

*Direct-installation programs are activities in which the utility (or its contractor) installs DSM measures in the facilities of participating customers; such programs generally cover low-cost measures, such as water-heater wraps and compact fluorescent lamps.

*Diversified demand is the average load (in $\mathrm{kW}$ ) across a group of customers or end uses.

*Diversified coincident peak demand effect is the change caused by the utility's DSM program in the demand for electricity at the time the utility experiences its system peak.

*Dropouts are customers who do not continue to participate in a program.

* Early replacement is the removal of equipment before it reaches normal retirement age and the substitution of new equipment for the old. 
* Early retirement refers to equipment that is taken out of service, but not replaced, before it reaches normal retirement age.

Economic potential is an estimate of the possible energy savings assuming that all energyefficient options will be adopted and all existing equipment will be replaced with the most efficient whenever it is cost-effective to do so, without regard to market acceptance.

*Eligible market is the subset of the total market that is qualified to participate in a program based on the program's participation criteria.

*Energy effects refer to the changes in aggregate electricity use (in GWh/year) for customers that participate in a utility DSM program.

*Energy-efficiency programs (sometimes called energy-conservation programs) are aimed at reducing the energy used by specific end-use devices and systems without degrading the services provided, thereby reducing overall electricity consumption ( $\mathrm{kWh}$ ), often without regard for the timing of program-induced savings. Such savings are generally achieved by substituting technically more advanced equipment to produce the same level of end-use services (e.g., lighting or warmth) with less electricity.

*Equipment cost is the price of components that the utility purchases directly for a DSM program, including the cost of DSM measures distributed free to participants.

*Existing buildings are structures that are in use as of the beginning of the current year.

Expensed refers to utility costs that are treated as current expenses rather than as capital costs; the utility cannot earn a return on expensed costs.

Free drivers are customers who take DSM-program-recommended actions because of the program, but who do not participate directly in the program (e.g., they do not claim rebates).

Free riders are customers who would have adopted program-recommended actions even without the program, but who participate directly in the program (e.g., they claim rebates).

*Fuel-switching programs encourage customers to change from one fuel to another for a particular end-use.

*Full-scale programs are mature, systemwide programs that are available to all of the eligible customers in the utility's service area.

*General information programs refer to utility efforts to inform customers about DSM options through such mechanisms as brochures, bill stuffers, TV and radio ads, and workshops. 
*Gross effect (sometimes called total effect) is the change in electricity use or demand experienced by a customer that participated in a utility DSM program, reported in $\mathrm{MWh} / \mathrm{year}$ and $\mathrm{MW}$ at the time of system peaks, both winter and summer, at the customer meter.

*Incentive is an award offered to encourage participation in a DSM program and adoption of recommended measures.

*Incentive programs offer cash or noncash awards to customers, trade allies, or employees to encourage participation in a DSM program and adoption of recommended measures.

Incremental cost is the difference in price, particularly between that of an efficient technology or measure and the alternative standard technology; in some early retirements and retrofits, the full cost of the efficient technology is the incremental cost.

*Incremental participation is the number of annual participants in the current year minus the annual participants in the previous year.

*Industrial sector is the group of nonresidential customers that provide products, including agriculture, construction, mining, and manufacturing.

*Integrated effect is the sum, over all the years of a program's operation, of the cumulative energy effects for a particular DSM program.

${ }^{*}$ Lifetime of programmatic energy effects is the median length of time (in years) that a DSM program produces energy effects; it is a function of both the lifetimes of the measures installed and operating practices.

*Load-building programs aim to increase electricity consumption, generally without regard to the timing of this increased usage.

* Load shape refers to the time-of-use pattern of customer electricity use, generally a 24-hour pattern or an annual (8760-hour) pattern.

* Load-shifting programs aim to move electricity consumption from one time to another (usually from the on-peak to off-peak periods during a single day).

Market potential is an estimate of the possible energy savings that would occur because of normal market forces (i.e., likely customer adoption over time of various actions without a DSM program).

* Marketing cost includes all expenses direcily associated with the preparation and implementation of the strategies designed to encourage participation in a program. 
* Monitoring and evaluation cost refers to expenditures associated with the collection and analysis of data used to assess program operation and effects.

* Net effect (sometimes called program effect) is the change in electricity use or demand for a participating customer that can be attributed to the utility DSM program, expressed in MWh/year and MW.

* New construction refers to buildings and facilities that are constructed during the current year; it may also include major renovations of existing facilities.

New-construction programs affect the design and construction of residential and commercial buildings and manufacturing facilities; such programs may also include major renovations of existing facilities.

* New participants are customers who take part in a program during the current year and did not participate in the program during the previous year.

* Noncash incentives are inducements in a form other than a rebate or cash payment; they may include low-interest loans, reduced equipment costs, bill credits or discounts, merchandise, or free services.

* Nonutility costs are those expenses incurred by customers and trade allies that are associated with participation in a DSM program, but that are not reimbursed by the utility.

* Normal replacement is the removal of worn-out (and perhaps obsolete) equipment and the installation of new equipment.

Operating and maintenance costs are noricapital, equipment-related expenses that continue over the life of the equipment; they include fuel costs as well as costs for maintaining and servicing equipment.

* Participant costs are those expenses associated with taking part in a DSM program paid by the customer and not reimbursed by the utility.

*Participants refers to the units used by a utility to measure participation in its DSM programs; such units of measurement include customers or households for residential programs and customers, floor area, or $\mathrm{kW}$-connected for commercial and industrial customers.

*Participation rate is the ratio of the number of participants in a program to the number eligible for the program, with both the numerator and denominator defined in the same units.

* Peak-clipping programs aim to reduce electricity demand $(\mathrm{kW})$ at certain critical times, typically when the utility experiences system peaks. 
Peak demand is the maximum rate of electricity use, expressed in kW.

Penetration (a measure of flow) is the ratio of the number of new units of a specific type installed to the total number of new units installed during a given time (e.g., the fraction of new air-conditioner sales that exceeds an energy-efficiency ratio of 10$)$.

Performance-based incentive is an award whose amount is linked to the recipient's DSM performance; usually calculated on the basis of $\& / \mathrm{kWh}$ or $\$ / \mathrm{kW}$.

* Pilot programs represent the initial phases of a full-scale program, the period during which a utility gains experience to run a successful full-scale program.

Potential market refers to the maximum effect (in MW or GWh) a DSM program could achieve; includes technical potential, economic potential, and market potential.

Rate discount is an incentive in the form of lower electricity prices for specified periods.

Rebate is money given to customers, contractors, homebuilders, or other trade .llies who make equipment choices to help defray the incremental cost of DSM measures.

* Repeats are customers from the prior year who continue to participate in a program.

Replacement programs affect the efficiency of new equipment and systems bought to take the place of comparable equipment.

* Residential sector is the group of customers to whom electricity is sold for household purposes, including space heating, water heating, air conditioning, lighting, and appliances in single-family, multifamily, and mobile homes.

* Retrofit is replacement or upgrading of equipment before it reaches normal retirement age.

Retrofit programs upgrade existing facilities and equipment.

Saturation (a measure of stock) is the ratio of the number of specific types of appliances or equipment to the total number of customers in that class or to the total number of appliances or equipment in use (e.g., the fraction of existing homes with double-pane windows).

*Site-specific information programs provide guidance on energy-efficiency and loadmanagement options tailored to a particular customer's facility; they often involve an onsite inspection of the facility to identify cost-effective DSM actions that could be taken.

Takeback (sometimes called snapback or rebound) refers to changes in customer behavior resulting in greater energy use stimulated by participation in a DSM program. 
Target market is the group of customers (a subset of the eligible market) that is the focus of utility marketing efforts.

Technical pocential is an estimate of possible energy savings based on the assumption that existing appliances, equipment, building-shell measures, and industrial processes will be replaced with the most efficient commercially available units regardless of cost.

Total market refers to all the customers in a given class.

*Total program costs are all expenses associated with a DSM program regardless of whether borne by the utility, participating customer, or trade allies. The costs paid by customers and trade allies are first adjusted for incentives from the utility to avoid double-counting costs.

*'Trade allies are organizations (e.g., architect and engineer firms, building contractors, appliance manufacturers and dealers, and banks) that affect the energy-related decisions of customers who might participate in DSM programs.

Turnover is the replacement of existing equipment that has reached the end of its useful life (same as normal replacement).

*Utility costs are all the expenses (administrative, equipment, incentives, marketing, monitoring and evaluation, and other) incurred by a utility in a given year for operation of a DSM program regardless of whether the costs are capitalized or expensed.

*Valley-filling programs typically seek to increase off-peak electricity consumption (without necessarily reducing on-peak demands). 


\section{INTERNAL DISTRIBUTION}

1. V. D. Baxter

2. L. Berry

3. D. S. Bjornstad

4. R. B. Braid

5. M. A. Brown

6. R. S. Carlsmith

7. R. Cantor

8. F. C. Chen

9. J. Christian

10. G. Courville

11. S. J. Dale

12. P. D. Fairchild

13. W. Fulkerson

14. M. B. Gettings

15. C. W. Hagan

16. L. J. Hill

17. E. Hillsman

18. E. Hirst

19. P. J. Hughes

20. C. R. Kerley

21. J. O. Kolb

22. M. A. Kuliasha

23. R. Lee

24. P. Leiby
25. J. M. MacDonald

26. L. N. McCold

27. V. C. Mei

28. W. R. Mixon

29. C. H. Petrich

30. S. Purucker

31. S. Rayner

32. J. H. Reed

33. D. E. Reichle

34. D. T. Rizy

35. M. Schweitzer

36. R. B. Shelton

37. G. G. Stevenson

38. J. N. Stone

39. J. Van Dyke

40. J. M. Veigel (ORAU)

41. D. B. Waddle

42. D. L. White

43. T. J. Wilbanks

44. ORNL Patent office

45. Central Research Library

46. Document Reference Section

47. Laboratory Records (RC)

48-50. Laboratory Records Dept.

\section{EXTERNAL DISTRIBUTION}

51. Bruce G. Buchanan, Computer Science Department, University of Pittsburgh, 206 Mineral Industries Building, Pittsburgh, PA 15260

52. Allan Hirsch, Vice President, Environmental Sciences, and Director, Washington Operations, 5109 Leesburg Pike, Suite 414, Falls Church, VA 22041

53. Martin Williams, Professor, Department of Economics, Northern Illinois University, DeKalb, IL 60115

54.-63. OSTI, U.S. Department of Energy, P. O. Box 62, Oak Ridge, Tennessee 37831 64. Office of Assistant Manager for Energy Research and Development, DOE/ORO, P. O. Box 2001 Oak Ridge, TN 37831-8600)

65.-1000. External Energy Efficiency and Renewables Section Distribution Mailing List and extra copies to E.M. Schorn, 450(0), H-19A 


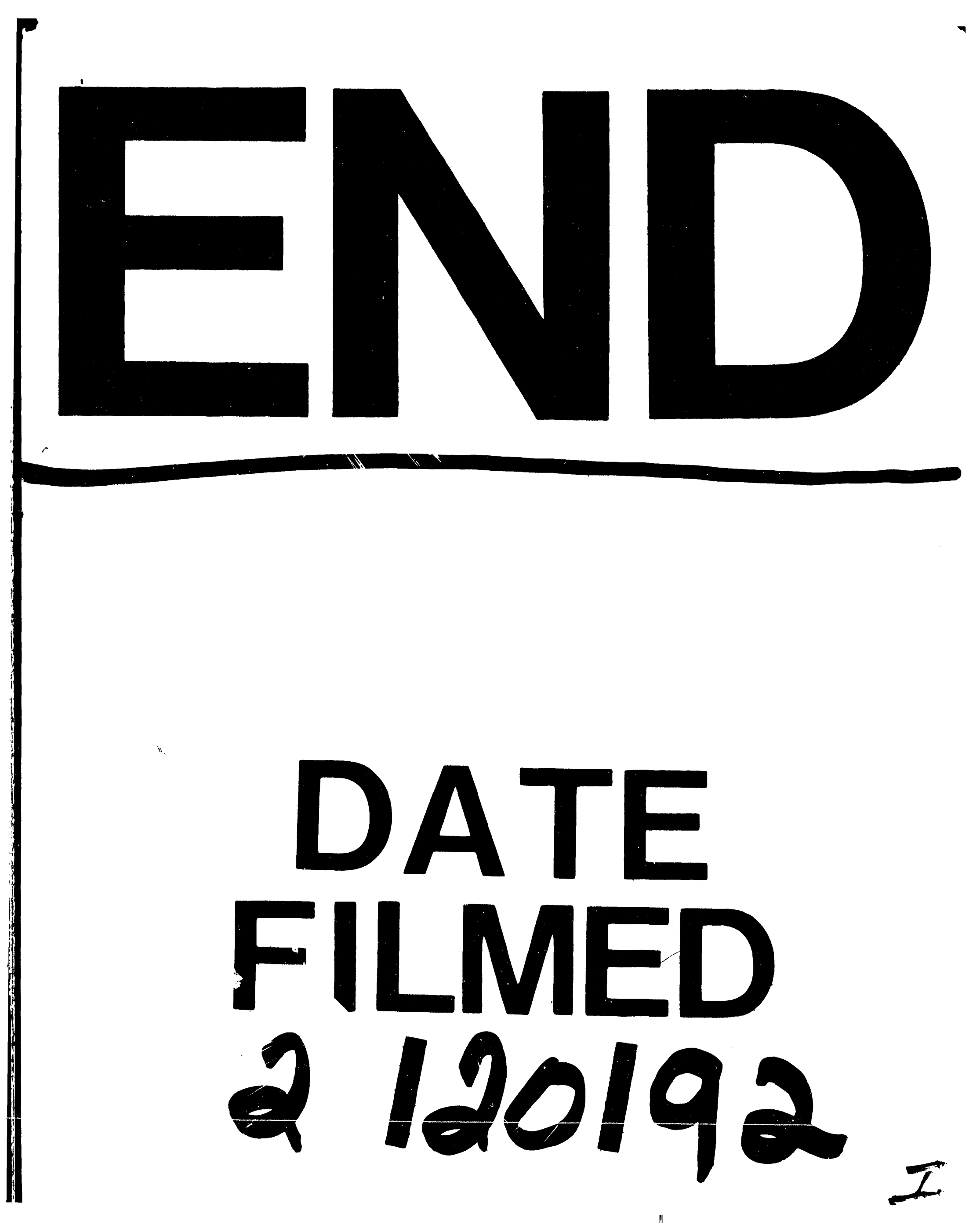




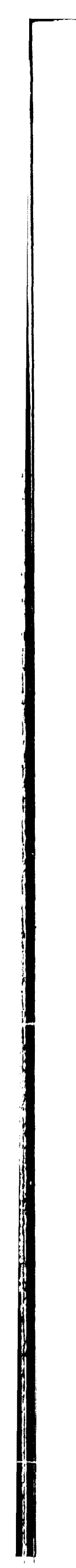

